\title{
A Real Time Ocean Forecast System for the North Atlantic Ocean
}

\author{
Avichal Mehra ${ }^{1, *}$ and Ilya Rivin ${ }^{2}$ \\ ${ }^{1}$ Environmental Modeling Center NCEP/NWS/NOAA, Camp Springs , MD 20746, USA \\ ${ }^{2}$ Science Applications International Corporation, Camp Springs, MD 20746, USA
}

Received 8 December 2008, accepted 16 April 2009

\begin{abstract}
The Real Time Ocean Forecast System (RTOFS) for the North Atlantic is an ocean forecast system based on the HYbrid Coordinate Ocean Model (HYCOM). HYCOM is the result of a collaborative effort between the University of Miami, the Naval Research Laboratory (NRL), and the Los Alamos National Laboratory (LANL), as part of a multi-institutional HYCOM Consortium for Data-Assimilative Ocean Modeling funded by the National Ocean Partnership Program (NOPP) to develop and evaluate a data-assimilative hybrid isopycnal-sigma-pressure (generalized) coordinate ocean model. This paper describes the RTOFS-Atlantic, an operational real time ocean nowcast/forecast system for the North Atlantic running daily at National Centers for Environmental Prediction (NCEP).
\end{abstract}

Key words: Ocean modeling, Operational oceanography, Hybrid models

Citation: Mehra, A. and I. Rivin, 2010: A real time ocean forecast system for the North Atlantic Ocean. Terr. Atmos. Ocean. Sci., 21, 211-228, doi: 10.3319/ TAO.2009.04.16.01(IWNOP)

\section{INTRODUCTION}

The National Oceanic and Atmospheric Administration (NOAA) Science Advisory Board on Ocean Modeling at NCEP provided a report to NOAA in July of 2004. In the report, NCEP was charged to become the computational backbone for operational ocean modeling within NOAA. In particular, NCEP's responsibility is to develop a national backbone capability for ocean, coastal and Great Lakes modeling as part of an integrated operational Earth System Model and to serve as the foundation for operational environmental prediction for a diverse array of customers and partners.

Short-term ocean "weather" forecasting was initiated as a core activity at National Centers for Environmental Prediction/National Weather Service (NCEP/NWS) in 1994 with the development of EC-ROFS (East Coast-Regional Ocean Forecast System) (Breaker et al. 2004). It was a prototype ocean forecast system based on the Princeton Ocean Model (Blumberg and Mellor 1987) which was implemented operationally at NCEP in March 2002. The EC-ROFS system covered only the North West Atlantic (the Gulf Stream region) at a $15 \mathrm{~km}$ nominal resolution. It provided products

\footnotetext{
* Corresponding author

E-mail: Avichal.Mehra@noaa.gov
}

for a daily nowcast and a two day forecast cycle.

RTOFS-Atlantic expands the scope of EC-ROFS in the Atlantic ocean with enhanced coverage (the entire eastern US seaboard and Gulf of Mexico) and increased resolution of 4 - $7 \mathrm{~km}$ (eddy resolving) in US coastal waters. Because of its configuration which includes tidal forcing, it is also capable of providing initial and boundary conditions for the ocean component of atmosphere-ocean coupled hurricane prediction models and storm-surge prediction models in the North Atlantic Ocean.

Some of RTOFS-Atlantic users within NOAA include the NWS regional forecast offices, Ocean Prediction Center (OPC), Tropical Prediction Center (TPC), Fisheries, National Ocean Service (NOS) and the Emergency Response Division (ERD) of Office of Response and Restoration (OR \& $\mathrm{R})$. Some of these issue daily marine forecasts (OPC, TPC) while others need initial and boundary conditions for high resolution physical (NOS) and bio-geo-chemical (ERD) models. Outside of NOAA, the US Coast Guard uses daily nowcasts/forecasts from RTOFS to determine surface currents and marine conditions to successfully conduct search and rescue operations. A few regional ocean observing systems [e.g., South East Atlantic Coastal Ocean Observing System (SeaCOOS), Gulf of Maine Ocean Observing Sys- 
tem (GoMOOS) etc.] also need far field boundary conditions from a basin-wide Atlantic model to force their coastal prediction systems. There are also a multitude of individual users who require having access to daily (and hourly) forecasts of currents, water levels, temperatures and salinity for recreation, marine research, marine operations, ocean exploration and ocean exploitation in the Atlantic Ocean.

Active development of RTOFS-Atlantic was started in 2004 and an operational system was implemented in December 2005. This system (hereafter called RTOFS) establishes an operational high resolution (eddy resolving) ocean forecast system for short-term forecasts (approximately one-week) for the North Atlantic ocean with offshore and US coastal waters well resolved. The domain of this system (shown in Fig. 1) extends from approximately $25^{\circ} \mathrm{S}$ to $72^{\circ} \mathrm{N}$ latitude and from $98^{\circ} \mathrm{W}$ to $16^{\circ} \mathrm{E}$ longitude. It covers the entire zonal extent of the Atlantic but does not include the Mediterranean Sea. It is important to note that the Labrador Sea and part of the G-I-N (Greenland-Iceland-Norwegian) Seas are included in the model domain. RTOFS provides, on a daily basis, 24 hour nowcasts and six-day forecasts of sea levels, currents, temperatures, and salinity. Emphasis is on the US coastal ocean, the Gulf of Mexico, and the Gulf Stream regions.

\section{HYBRID COORDINATE OCEAN MODEL (HY- COM)}

HYCOM is the model component of RTOFS. It is a primitive equation numerical model formulated on a staggered Arakawa "c" grid. The operational model employs a non-slab mixed layer model given in Canuto et al. (2001). The unique needs of the operational system at NCEP dictate that the ocean model must be versatile enough to capture processes at different length and spatial scales from the coast to the stratified deep ocean. Hence, both horizontal and vertical resolution requirements in HYCOM must be considered.

Hybrid vertical coordinates now enjoy wide support in ocean modeling research and operations communities around the world. It is widely accepted that while the deep stratified ocean is best represented by isopycnal coordinates (i.e., using density to track the vertical coordinate), constant z-levels (i.e., constant pressure levels, isolevels) are best at representing the upper mixed layer, and the sigma coordinates (terrain-following) are often the best choice for coastal regions (Chassignet et al. 2006). HYCOM can be configured to combine all three coordinate systems by choosing the optimal distribution of its hybrid coordinates at every time step. Its coordinates can be configured such that a dynamically smooth transition can be made from the sigma coordinates in the coastal ocean, to pressure (isolevel) coordinates in the mixed surface layer, and to isopycnal layers at deeper levels. Further details of the hybrid scheme can be found in Bleck (2002).

For RTOFS, the coastal ocean needs to be well resolved along with the ability to well represent water mass characteristics and currents in the deep ocean. However, the availability of computational resources limits the number of vertical levels that can be used.

\section{DESCRIPTION OF THE SYSTEM}

\subsection{Grid Configuration}

\subsubsection{The Hybrid Vertical Coordinate System}

A set of assigned target densities (equal to the number of vertical levels) as well as minimum and maximum allowable shallow and deep water depths need to be specified before the HYCOM model is run. The HYCOM grid-generator algorithm, then, using the fact that all of the layers have an assigned target density, moves grid points vertically to improve isopycnal alignment of coordinate surfaces. There are three different regions: shallow-z, deep-z, and terrain following (sigma coordinates) as shown in Fig. 2. There are three parameters governing the shallow-z region: minimum thickness $\delta_{s}^{m i n}$, maximum depth $\delta_{s}^{\max }$, and stretching factor $f_{s}$. There are also three corresponding deep-z region parameters: minimum thickness $\delta_{p}^{\min }$, maximum depth $\delta_{p}^{\max }$, and stretching factor $f_{p}$. Another parameter, $N_{\sigma}$ (or number of sigma levels), is used to determine the transition from the shallow-z region to the sigma-coordinate region, and from the terrain-following region to the deep- $\mathrm{z}$ region. The transition from the shallow-z region to the sigma-coordinate occurs at the depth, $d_{1}$, defined by

$d_{1}=\sum_{1}^{N_{\sigma}} \max \left(\delta_{s}^{\max }, \delta_{s}^{\min }, f_{s}^{N_{\sigma}-1}\right)$

If the water depths are always greater than the depth in Eq. (1), then no shallow-z region exists. In the NCEP operational configuration, we ensure that no shallow-z region exists and the configuration is such that there is a direct transition from terrain-following region to deep-z region. Similarly, the transition from the terrain following coordinate to the deep-z region can be found by applying the deep-z parameters to the above equation or

$d_{2}=\sum_{1}^{N_{\sigma}} \max \left(\delta_{p}^{\max }, \delta_{p}^{\min }, f_{p}^{N_{\sigma}-1}\right)$

The deep-z region is defined as the region where the bathymetry is greater than the depth of the $N_{\sigma}$ (last) interface in the $\left(\delta_{p}^{\min }, \delta_{p}^{\max }, f_{p}\right)$ z-coordinate system. The reader is referred to Halliwell (2004) for more details on the hybrid coordinate system and to Bleck (2002) for some specific examples of realignment of coordinate surfaces based on water mass movements. 


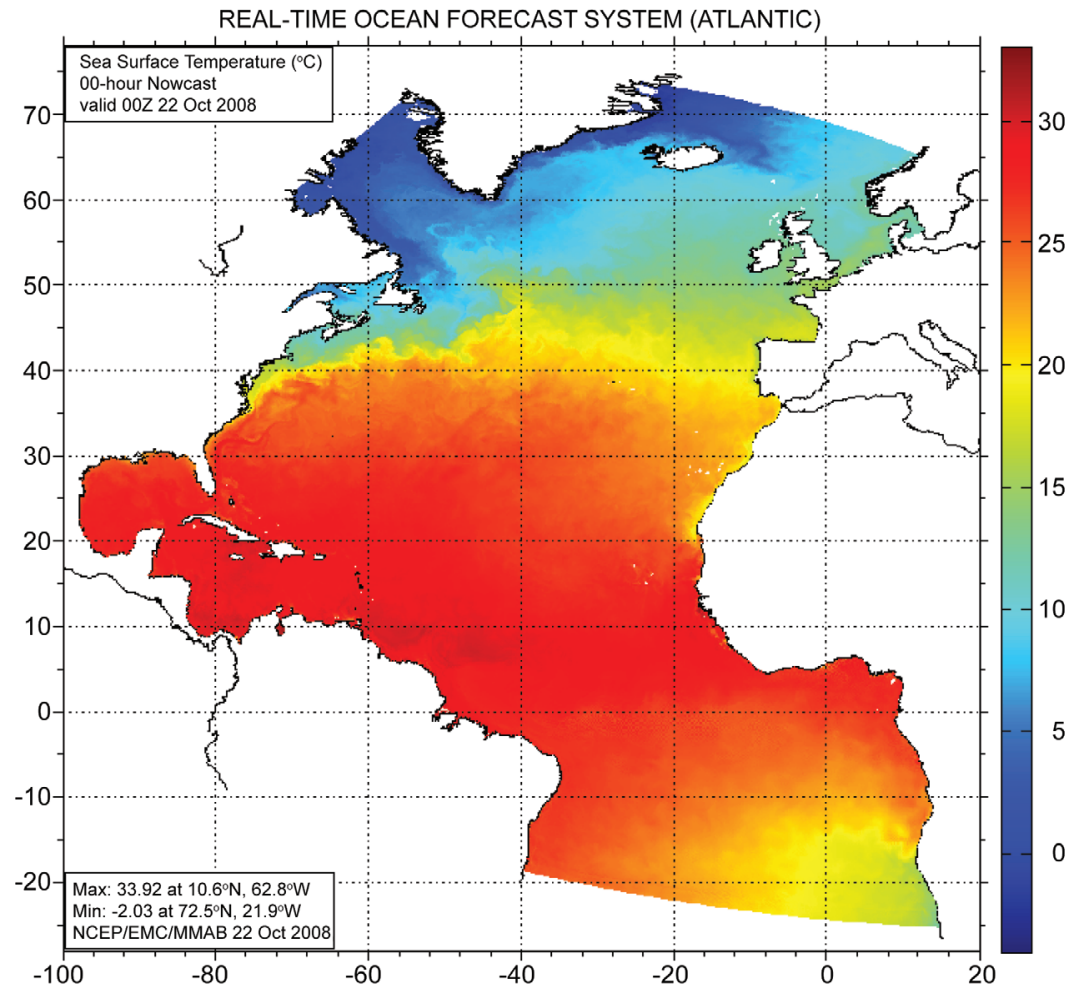

Fig. 1. Extent of the domain for the RTOFS-Atlantic.

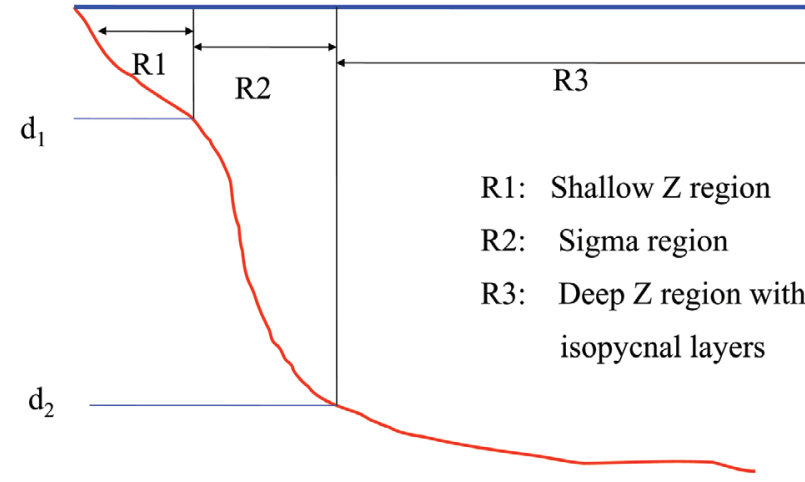

Fig. 2. The hybrid vertical coordinate system for RTOFS.

\subsubsection{Horizontal Grid and Bathymetry}

The model uses curvilinear coordinates in the horizontal. The grid is telescopic and orthogonal and varies from approximately $4-5 \mathrm{~km}$ near the US East Coast to almost $17 \mathrm{~km}$ near West Africa (Fig. 3). The total horizontal grid size consists of $1200 \times 1684$ points. This grid provides the highest resolution for the Gulf of Mexico and along US Eastern Seaboard and lowest near the South-West African coastline.
The bathymetry (Fig. 4) is interpolated from the ETO$\mathrm{PO} 2$ dataset $^{1}$ with the coast defined at $3 \mathrm{~m}$ depth. Coastlines from National Geospatial Data Center (Wessel and Smith 1996) are used to resolve most coastal features along the eastern seaboard and in the Gulf of Mexico. Discrepancies between the chosen bathymetry and coastlines are eliminated by extrapolation of depth data to the chosen coastline.

\subsubsection{Criteria for the Selection of Parameters and Tar- get Densities}

The criteria used for the selection of the parameters and target densities was dictated by the needs for RTOFS. In order to maintain deep water circulation patterns, proper representation of the many significant water masses is necessary. Hence, a careful study of the isopycnals chosen by Reid (1994) and Lozier et al. (1995) revealed a set of isopycnals that represent important water circulation elements (such as the Deep Western Boundary Current, Gulf Stream etc.). These isopycnals need to be included. Second, a normal mode analysis of the vertical water mass distribution was conducted (following Chelton et al. 1998) for eleven different regions, and another set of isopycnals (or target densities) was obtained. Third, the processes occur- 


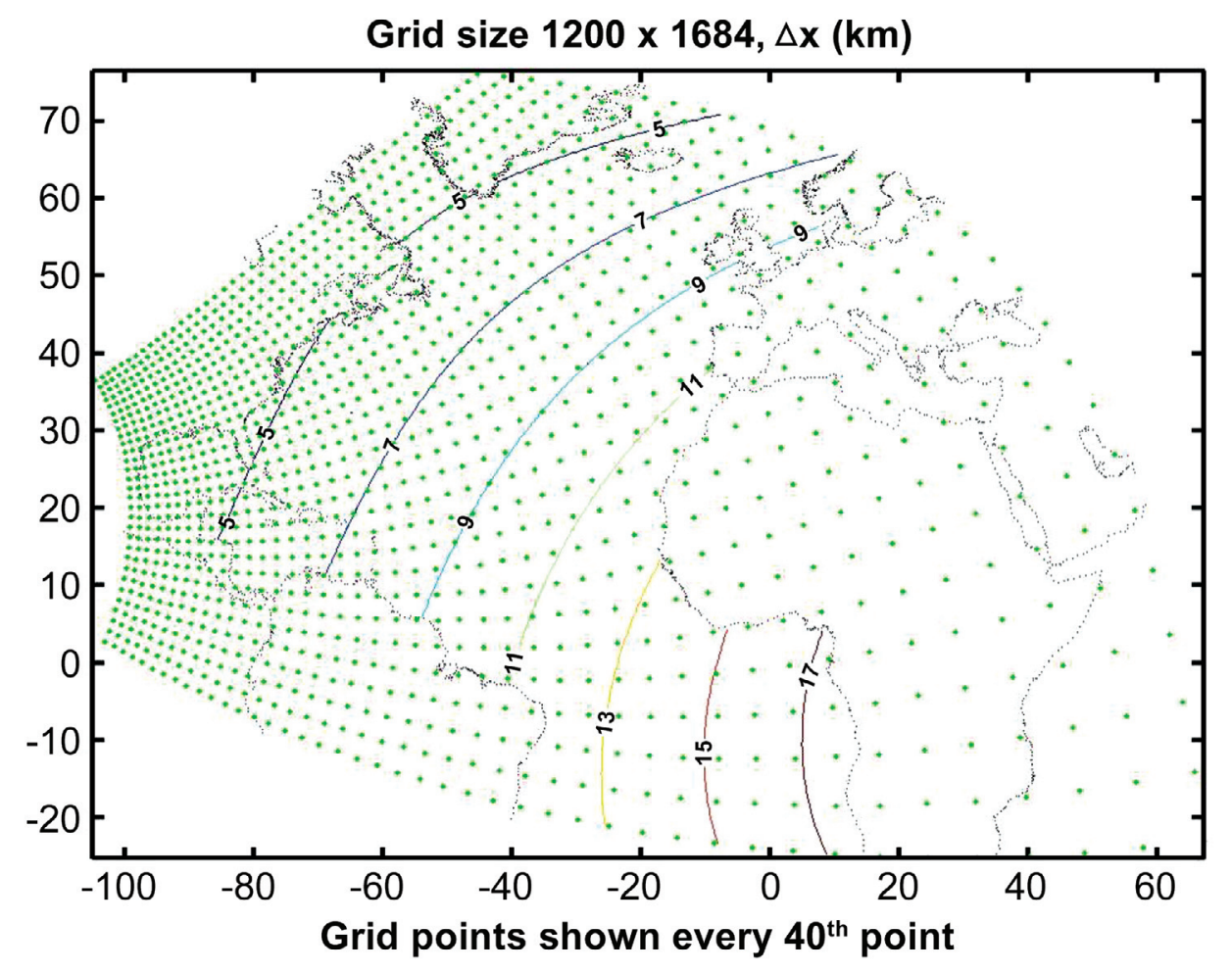

Fig. 3. Grid resolution for RTOFS-Atlantic.

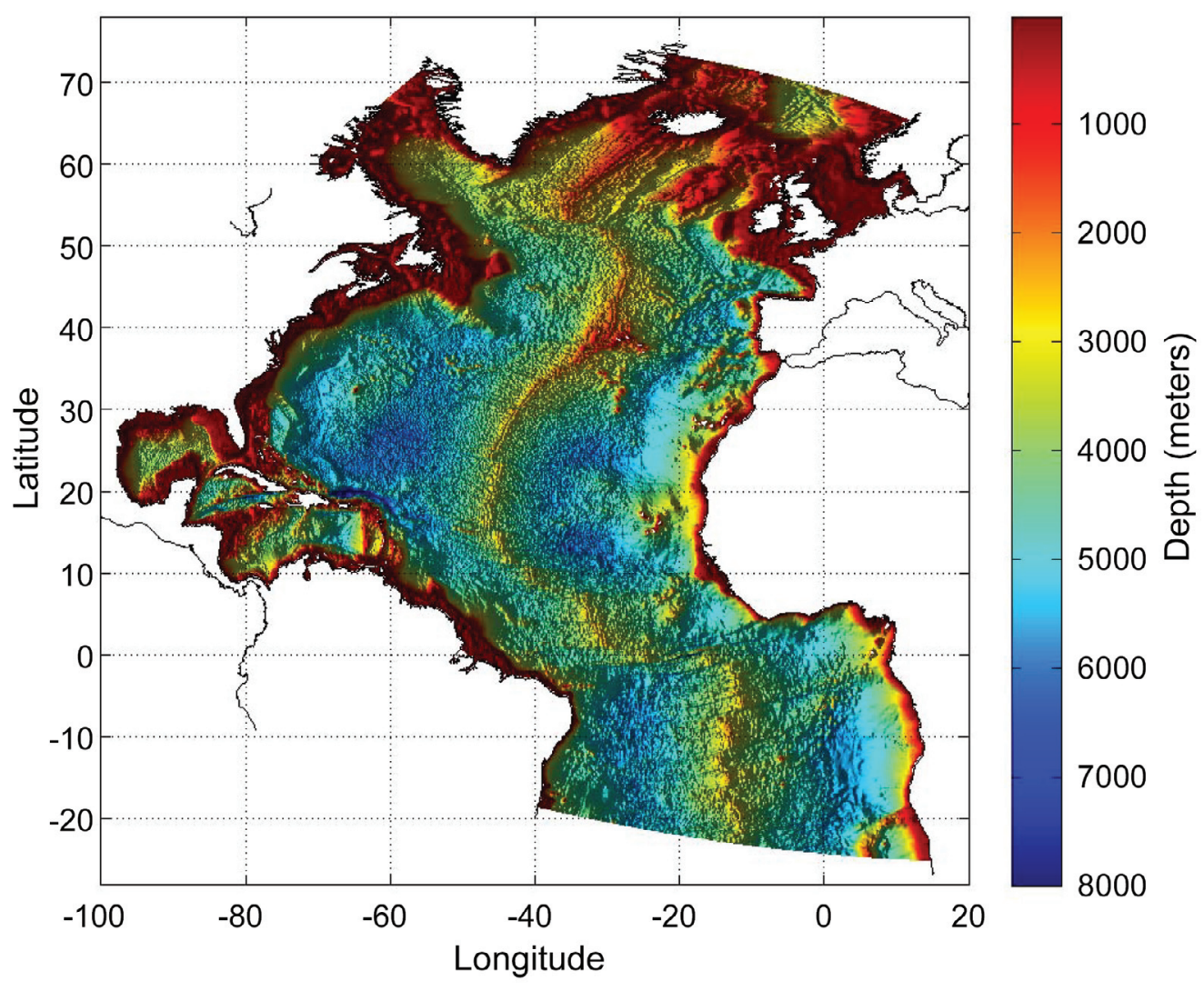

Fig. 4. Bathymetry for RTOFS-Atlantic. 
ring along the coastal ocean need to be well resolved. Thus, the hybrid parameters were chosen so that much of the Eastern US coastal waters are represented by sigma coordinates. Finally, a set of isopycnal targets were obtained so that the Denmark Strait overflow, the Iceland Faroe overflow and Mediterranean overflow were well resolved. All the different isopycnal targets are then combined and 26 target densities are chosen so that most of the features can be resolved.

\subsection{Surface Forcing}

Air-sea fluxes are calculated from the the surface and near-surface predictions from NCEP's operational Global Forecast System (GFS) (Moorthi et al. 2001). GFS is based on NCEP's spectral atmospheric general circulation model [see AGCM, (Satoh 2004, chapter 21) for detailed description of the spectral approach to atmospheric primitive equation modeling]. NCEP's AGCM has 64 vertical layers and is implemented in two horizontal resolutions: high (T382) and low (T190). Here Tnnn refers to a spectral expansion that is truncated triangularly at the nnnth number of spectral harmonics [triangular truncation is defined on Satoh (2004), p. 533]. Daily global 24 -hour nowcasts and 0 to 180 -hour forecasts are produced in high resolution, and 180 to 384 hour forecasts are produced at a lower horizontal resolution. The RTOFS forecast cycle starts immediately after $00 \mathrm{Z}$ GFS forecast cycle is completed and uses the latest available atmospheric nowcast and forecast fields to force the ocean model, namely surface momentum flux (wind stress), precipitation rate, surface pressure, surface long-wave and short-wave radiation fluxes (upward and downward), wind speed at $10 \mathrm{~m}$, air temperature at $2 \mathrm{~m}$, and specific humidity of air at $2 \mathrm{~m}$. The difference in heights of variables $(2 \mathrm{~m}$ vs. $10 \mathrm{~m}$ ) is as per the location of instruments for taking measurements on a standard weather station which are routinely used for evaluating model results. All surface and near-surface fields are instantaneous and are produced every three hours on a $1152 \times 576$ Gaussian grid [see Satoh (2004), p. 537 for definition of Gaussian latitudes]. The exceptions are radiation fluxes and precipitation rate, which are available as instantaneous fluxes at the beginning of forecast cycle and thereafter as three-hour averages for the remainder of the cycle. Since, having instantaneous forcing is extremely important for severe weather applications (e.g., hurricane events), time-averaged atmospheric fields are algebraically interpolated in time to provide approximate instantaneous air-sea forcing fields every three hours.

The depth of short-wave radiation penetration in the ocean is highly dependent upon water clarity. According to Jerlov (1976), water clarity can be described by integer numbers from 1 to 5 (Jerlov water types), with 1 corresponding to the clearest water. Currently in RTOFS, Jerlov water type is assumed to be constant and equal to 2 for the whole region. From Halliwell (2001), solar radiation penetrating through a model level $k\left(S_{k}\right)$ can be calculated as:

$$
S_{k}=S_{s}\left[r \exp \left(-p_{k+1} \beta_{r}^{-1}\right)+(1-r) \exp \left(-p_{k+1} \beta_{b}^{-1}\right)\right]
$$

Here $S_{s}$ is the incoming surface radiation at the ocean surface, $r$ is fraction of red light, $\beta_{r}$ and $\beta_{b}$ are penetration length scales of red and blue light correspondingly and $p$ is the surface pressure.

Momentum forcing is provided via the surface wind speeds from atmospheric GFS. In order to retain an important negative feedback between turbulent (latent and sensible) air-sea heat fluxes, the bulk parameterization of surface latent heat flux and sensible heat flux is used as recommended by Kara et al. (2000) and Kara et al. (2002).

\subsection{Open Boundaries}

Although, open boundaries present an ill-posed problem for hydrostatic models (Oliger and Sundstrom 1978), they are needed for accurate solutions away from the boundaries. As such, the numerical effects caused by boundaries and imposed boundary conditions should be limited within pre-determined buffer zones. Methods for specifying threedimensional open boundary conditions abound in the literature (for a review see Palma and Matano 2000), but the selection of appropriate forcings at the boundaries has been found to be application specific (Orlanski 1976; Stevens 1991; Penduff et al. 2000; Treguier et al. 2001 etc.). The boundary conditions for RTOFS can be differentiated between those for the internal (baroclinic) mode and for the external (barotropic) mode of solution.

\subsubsection{Baroclinic Boundary Conditions}

The baroclinic or internal mode boundary conditions consist of:

(a) Extrapolation of velocity fluxes for advection and momentum. The horizontal velocity fluxes for advection and momentum terms on the boundaries are extrapolated in the upwind direction. This is done for both $u$ and $v$ components of the flowfield.

(b) Relaxation of mass fields, i.e., $\mathrm{T}$ (temperature), $\mathrm{S}$ (salinity) and I (interface thickness) in the buffer zones. This can be expressed as:

$$
\begin{aligned}
& T_{k}^{t+1}=T_{k}^{t}+\Delta t \theta\left(\widetilde{T}_{k}^{t}-T_{k}^{t}\right) \\
& S_{k}^{t+1}=S_{k}^{t}+\Delta t \theta\left(\widetilde{S}_{k}^{t}-S_{k}^{t}\right) \\
& I_{k}^{t+1}=I_{k}^{t}+\Delta t \theta\left(\widetilde{I}_{k}^{t}-I_{k}^{t}\right)
\end{aligned}
$$

where index $t$ denotes time, $\sim$ represents values from 
climatology, $\Delta t$ is the baroclinic time step, $k$ is the layer number and $\theta^{-1}$ is the relaxation time scale. The width of buffer zones in number of grid points and values of $\theta^{-1}$ in days are determined by the ability of these buffer zones to maintain appropriate water mass distributions near the boundary. The values chosen for each boundary are listed in Table 1.

The above equations are satisfied for all hybrid (nonisopycnal) layers. For isopycnal layers, only salinity and interface thickness are relaxed to climatological values while temperature is calculated from the equation of state.

\subsubsection{Barotropic Boundary Conditions}

The algorithm and sources for specifying barotropic (external mode) boundary conditions are discussed in the following subsections.

\subsubsection{Algorithms}

Based upon adopted numerical schemes for discretization, the algorithms for the boundary conditions must be stable and closely target the boundary values. The discretization of the governing equations in HYCOM is such that only velocity needs to be specified on the boundary grid points. However, in order to achieve an accurate barotropic flow across the boundary, the surface elevation (pressure gradient) is specified as well.

For example, Fig. 5 shows the grid points involved for the model-west boundary. Using the theory of characteristics (Browning and Kriess 1982), the incoming invariant (from the exterior) can be written as:

$u_{o b s}+c \eta_{o b s}$

The subscript $o b s$ denotes the observed value and $c$ refers to the celerity of the incoming information, which when multiplied as a factor to $\eta$, the sea surface elevation, allows us to treat sea-surface elevation as velocity. In the above equation, $u$ is the normal velocity.

Following the method of Flather (1976), gradients can be set to zero over the boundary, i.e., the incoming information is imposed on the boundary in such a manner that no contribution from reflection can be present at the boundary. This means:

$u_{b}+c \eta_{b}=u_{o b s}+c \eta_{o b s}$

Here subscript $b$ refers to the boundary point and again obs signifies a prescribed (observed) value.

From Eq. (6), an equation for the velocity (or transport) at the boundary can be obtained: $u_{b}=u_{o b s}+c\left(\eta_{o b s}-\eta_{b}\right)$

The value of $\eta_{b}$ is already known from the model at this stage. However, this may not be physically consistent with the equation for the velocity. If $\eta_{b}$ is not close to $\eta_{o b s}$, the velocity will not target the true velocity, which we take to be the observed velocity. We have to therefore include a constraint on the sea surface level which is imposed on the boundaries, which makes use of both $\eta_{b}$ and $\eta_{o b s}$ in a weighted fashion:

$\eta_{b}^{\prime}=\alpha \eta_{o b s}+(1-\alpha) \eta_{b}$

where $\alpha$ is the weight. This modified value of sea surface elevation $\eta_{b}^{\prime}$ is then used in Eq. (7) which yields:

$u_{b}=u_{o b s}+c\left(\eta_{o b s}-\eta_{b}^{\prime}\right)$

In this way it is seen from the equation for $u$ that the velocity will target the observed velocity, unless $\eta_{b}$ differs significantly from $\eta_{\text {obs }}$. The value of $\alpha$ is set a priori to $\alpha=0.1$ in the operational RTOFS.

Herein the observed values for transport and elevations on the open boundaries are defined as a sum of contributions from tides as well as the low frequency component of the barotropic mode (as described in the next section). If tides are not included, only the low-frequency part is main-

Table 1. The width of buffer zones (in grid points) and the relaxation time scale (in days) near each open boundary.

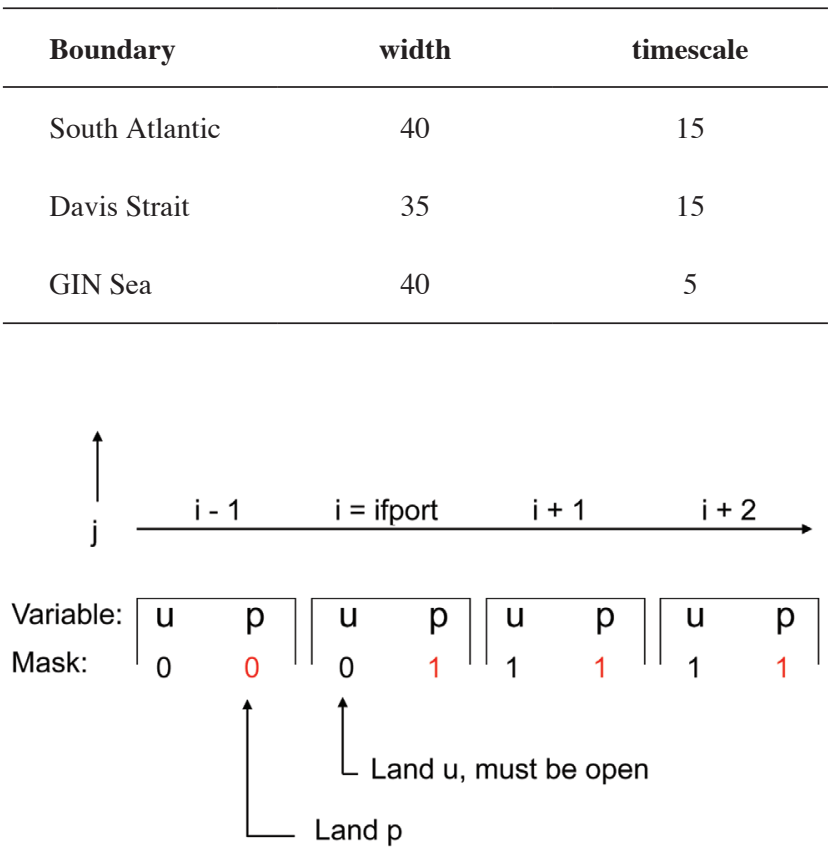

Fig. 5. Grid points on the model-west open boundary. The "ifport" location is for the boundary point. 
tained at the boundary.

The boundary values on the other open boundaries are obtained similarly with only the sign changing to reflect the direction of flow into or out of the domain. The information coming from inside is not allowed to reflect at the boundary but is instead allowed to go across the boundary smoothly by imposing zero gradients. Thereby only information from the outside passes into the domain.

A two-invariant algorithm has also been used, where the two characteristics for the model-west boundary are given by:

$\Gamma^{o b s}=u_{e x t}-\gamma \eta_{b}$

$\Gamma_{+}^{o b s}=u_{b-1}^{o b s}+\gamma \eta_{b}^{o b s}$

where $\gamma=(g H)^{1 / 2}$ is the celerity with $\mathrm{H}$ water depth and $u_{e x t}$ is approximated by a linear extrapolation on the boundary transport:

$h_{b-1} u_{e x t}=\frac{1}{2}\left(3 h_{b} u_{b}-h_{b+1} u_{b+1}\right)$

where $h$ is the water depth defined at velocity grid points. Superscript $o b s$ and subscript $b$ are same as defined earlier.

For all the cases, the tangential velocity $v$ at the boundary grid point is given by:

$v_{b}=v_{o b s}$

where once again subscript $b$ refers to the boundary point and $o b s$ signifies a prescribed (observed) value.

\subsubsection{Low Frequency Boundary Conditions}

The non-tidal low frequency barotropic conditions involve tracking of the barotropic (external) mode with prescribed normal transports and water elevations. At each open boundary, the absolute geostrophic velocity can be determined by either:

(a) assuming a "level of no motion" at some known depth, or

(b) constraining by the mean sea surface elevation at the boundary points.

For case (a), the following thermal wind relations can be applied to climatology to calculate normal velocities and elevations at open boundaries.

$\frac{\partial(\rho f \bar{V})}{\partial z}=-g \frac{\partial \rho}{\partial n}$

where $\rho$ is the potential density, $f$ is the coriolis term, $\bar{V}$ represents the velocity field, $g$ is the gravity and $n$ is the direction normal to the boundary.

The mean of elevations on each open boundary is replaced with the Mean Dynamic Topography (MDT). The dynamic topography chosen for this purpose is the one generated by Niiler et al. (2003) by using near-surface velocity observations from drifters over a time period of 11 years (1992 - 2002).

The specifics of each open boundary which are shown in Fig. 6 are detailed below:

\section{The Greenland-Iceland-Norwegian (GIN) Seas:}

This open boundary is characterized by both inflow and outflow. Outflow occurs near the eastern shelfbreak due to the Norwegian Coastal current (Mork 1981) which in turn is fed by the North Atlantic Drift. Inflow through the western boundary is controlled by the East Greenland Current and is estimated to be $25 \pm 4 \mathrm{~Sv}$ (Woodgate et al. 1999). Since net inflow for this boundary is mostly barotropic (Woodgate et al. 1999), the sea level data is taken from the chosen MDT and target barotropic velocities calculated using geostrophy.

\section{The Davis Strait:}

This open boundary is also characterized by both inflow and outflow. Outflow mostly occurs through the eastern Davis Strait controlled by the Labrador Sea Gyre (2 - $6 \mathrm{~Sv}$ as per Tang et al. 2004), while inflow through the western half is regulated by water masses from the Canadian Arctic Archipelago (0 - 2 Sv from Cuny et al. 2005). The net transports are estimated to be $(0-4 \mathrm{~Sv})$ from Dunlap and Tang (2006).

A level of no motion is assumed to be that of $800 \mathrm{~m}$ for calculating dynamic heights and geostrophic velocities. The mean sea level is replaced by the mean MDT data.

\section{The South Atlantic:}

This region has a complex current structure involving both inflow and outflow. Most inflow and outflow occur over shelf breaks on both sides (Brazil and Africa). The Brazil current outflow and DWBC (Deep Western Boundary Current) inflow dominate the Brazil shelf break (Stramma and Schott 1999). The African shelf break experiences outflow from waters leaking from the Angola Gyre and from relatively shallow NADW (North Atlantic Deep Water) (Stramma and England 1999) and inflow from the Benguela current. The net transport estimates across this boundary vary between a net inflow of $10-35 \mathrm{~Sv}$.

A level of no motion is assumed at $2500 \mathrm{~m}$ for calculating dynamic heights and geostrophic velocities. Once again 


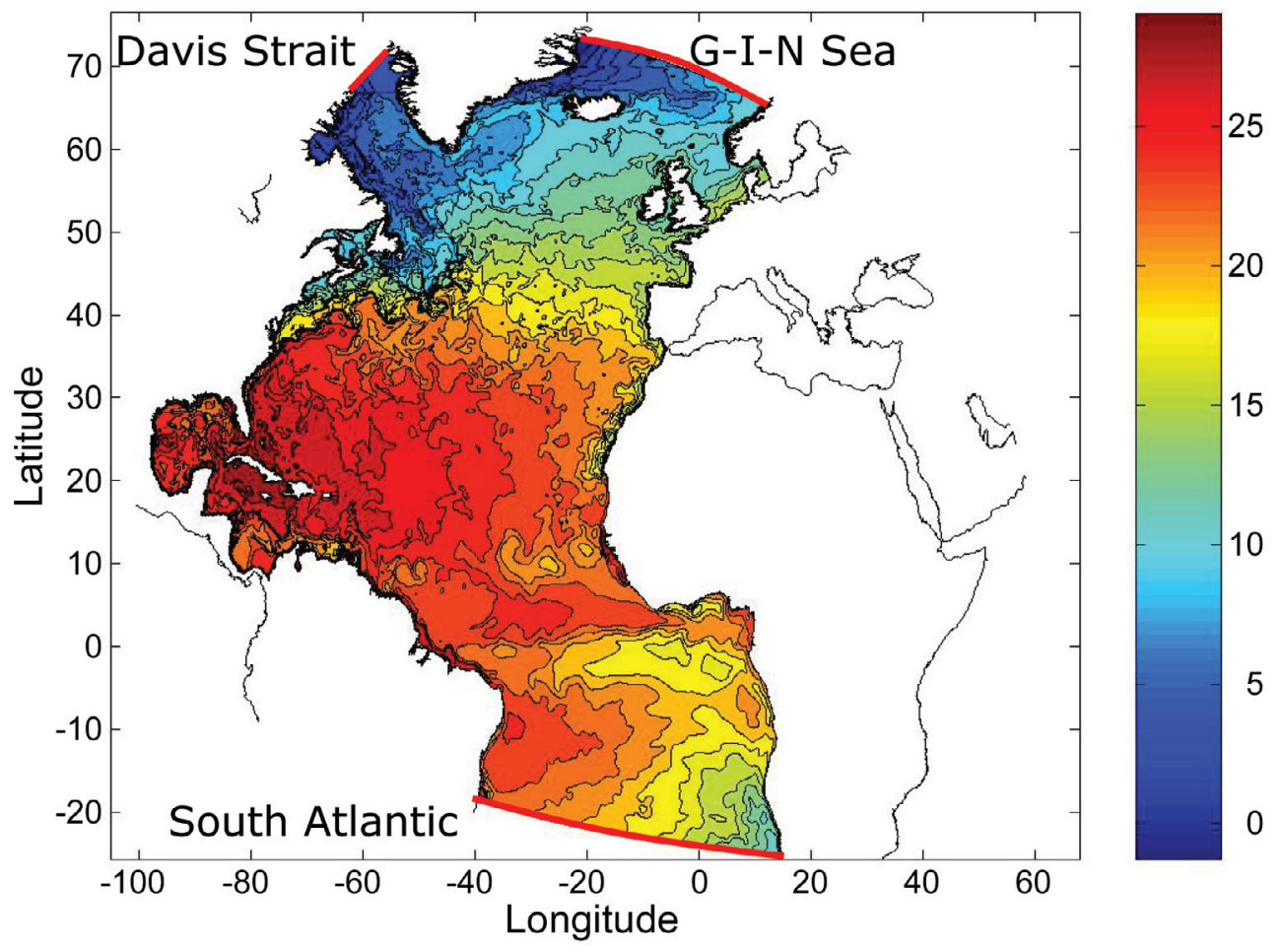

Fig. 6. The Open boundaries for RTOFS-Atlantic.

the mean sea level is taken from Niiler et al. (2003). The chosen "levels of no motion" were adjusted to limit the net influx into the domain to within $1 \mathrm{~Sv}$.

\subsection{Tides}

Astronomical tidal forcing from four semi-diurnal $\left(\mathrm{M}_{2}\right.$, $\left.\mathrm{K}_{2}, \mathrm{~N}_{2}, \mathrm{~S}_{2}\right)$ and four diurnal $\left(\mathrm{O}_{1}, \mathrm{~K}_{1}, \mathrm{P}_{1}, \mathrm{Q}_{1}\right)$ tidal frequencies have been included in RTOFS.

The tidal forcing includes the response from both the stationary (local) as well as the transient (remote) signal. The stationary response can be written as (Reid 1990):

$\eta_{\text {resp }}=\psi_{m j} \cdot \cos \left[\sigma_{m j} \cdot t_{0}+\chi_{m j}-\delta_{m j}(k, l)\right]$

In the above, $\psi$ is the amplitude of the tidal response at a given location for each constituent. This amplitude is also called the co-amplitude. $\delta$ is the phase lag of the response (therefore negative) and is also called the co-phase. The subscript $m$ refers to the frequency band where $m=0$ is the mean (or long period) frequency band, $m=1$ is the diurnal frequency band and $m=2$ is the semidiurnal frequency band. The subscript $j$ denotes each constituent included within each frequency band, i.e., components $\mathrm{M}_{2}, \mathrm{~K}_{2}, \mathrm{~N}_{2}$ and $\mathrm{S}_{2}$ in the frequency band $m=2$ and $\mathrm{O}_{1}, \mathrm{~K}_{1}, \mathrm{P}_{1}$ and $\mathrm{Q}_{1}$ in the frequency band $m=1 . k$ and $l$ are the coordinates of a given location while $\sigma$ and $\chi$ are the cyclic frequency and the astronomical argument for each constituent respectively. These are identical to those used for the boundary (transient) tidal forcing. $t_{0}$ is the time from a certain origin, which must be consistent with how $\chi$ is calculated (i.e., from the beginning of the computational year). It is also necessary to include the contribution to the tidal response signal from long-period oscillations (for example, the 18.6 year lunar nodal period of the inclination of the lunar orbit to the equatorial plane). This is accomplished with the inclusion of nodal corrections. The variations in the expressions for solid earth tides are represented with associated Love numbers for each constituent (Kantha and Clayson 1999). The effect from the deformation of the elastic earth due to the rearranging of mass in the ocean (the ocean loading tide) is also included (Foreman et al. 1993). This effect depends on the actual sea-surface height, and is used to modify the surface pressure gradient in both the barotropic and the baroclinic momentum equations.

To avoid any initial transients obtained when imposing the full body tidal signal at once, the signal is ramped up in time. This is done by multiplying the body-tide force with a ramp-factor which increases exponentially with time:

$R=1-e^{-s}$

In the above equation, $R$ is the ramp-factor and $s$ is given by: 
$s=\frac{5\left(t_{m}-t_{r}\right)}{D}$

where $t_{m}$ is the current model time in days, $t_{r}$ is the start date of ramping and $D$ is the user specified time period of ramping in days. Even though the above expression has a small discontinuity, it does not result in any strong transients.

On the open boundaries, the transient (remote) tideinduced elevations and transports must also be accounted for in order to obtain an accurate tidal response. These are specified on the boundary from the TPX06 database (Egbest and Erofeeva 2002) for those points which have at least two adjacent active (wet) points. The same four semi-diurnal $\left(\mathrm{M}_{2}, \mathrm{~K}_{2}, \mathrm{~N}_{2}, \mathrm{~S}_{2}\right)$ and four diurnal $\left(\mathrm{O}_{1}, \mathrm{~K}_{1}, \mathrm{P}_{1}, \mathrm{Q}_{1}\right)$ components as before are used.

\subsection{Rivers}

The rivers are treated in RTOFS as fresh water fluxes at the coastline and the transports are distributed over depth such that the minimum salinity is bounded ( $\geq 1 \mathrm{ppt}$ ). Also, the sea surface elevation is allowed to adjust due to river outflow volume changes. The data for river outflows for about 500 stations is updated daily from the United States Geological Service (USGS) daily streamflow conditions which are provided publicly at the URL: http://waterdata. usgs.gov/nwis/rt. If the data is missing then river climatology given by Global River Discharge (RivDIS) (Vorosmarty et al. 1996) is used as the default value. Climatological values from RivDIS are also used for the forecast cycle. In the near future, predictions from NCEP's NLDAS (Mitchell et al. 2004) hydrometeorological system will be used to specify the riverine outflows during the forecast cycle.

\subsection{Assimilation of Observations}

The objectives of data assimilation in RTOFS are to improve the forecasts of surface and sub-surface ocean features using remotely sensed observations of sea surface temperature, sea surface heights, in situ temperature, salinity profiles, and model estimates at each grid point.

\subsubsection{Sea Surface Temperature}

At present, realtime sea surface temperatures (SST) from the AVHRR (Advanced Very High Resolution Radiometer) and GOES (Geostationary Operational Environmental Satellite) are used for SST data assimilation into RTOFS daily using a method where time interpolated analysis values are nudged towards observations during nowcast in the mixed layer. For quality control purposes, mean and standard deviations are taken from the PATHFINDER version 5 (Vazquez et al. 1996) climatology.
Two two-dimensional variational analyses (Chao et al. 2003) are performed: one for yesterday and one for today during the daily nowcast cycle. The model SST is nudged to the time interpolated temperature analysis while integrating from yesterday to today. The preparation of GOES data also includes a spatially varying bias removal algorithm (Lozano and Liu 2010).

\subsubsection{Sea Surface Height}

The distribution of water masses and circulation are often reflected on sea surface height (SSH) variations. This allows the inference of the ocean internal structure from sea surface height observations. The altimeter patterns acquired over a ten day window allows us to resolve mesoscale features of the circulation on a limited basis. Sea Level Anomalies (SLA) derived daily in realtime from JASON, GFO and ENVISAT altimeter data are used for SSH data assimilation in RTOFS. The assimilation method includes a multi-scale two-dimensional variational analysis of the deviations of the model sea surface height from the observed absolute sea surface height. The altimeter sea surface height anomalies are used along with mean dynamic topography estimates from historical data (Rio and Hernandez 2004). Then, a vertical one-dimensional variational analysis (akin to Cooper and Haines 1996) of SSH and layer thickness is employed to update the model vertical structure while preserving momentum. The error covariance for this purpose is computed from coarser simulations as a function of spatial location in the horizontal where the vertical grid parameterizations are as outlined in section 3.1.1.

For quality control purposes, an observation is accepted if both the anomaly from the climatological mean and from the model nowcast are within a priori defined factor of standard deviation of the climatological variability.

\subsubsection{Profiles}

Temperature and salinity profiles are collected in realtime over a ten day window from Argo floats, CTD (Conductivity, Temperature, Depth) casts, XCTD (eXpendable CTDs) casts and from moored arrays. At present, only data which has both temperature and salinity are used, but in the future, temperature profiles will be assimilated along with synthetic salinity profiles derived from algorithms based on correlations with sea surface height and T-S diagrams from climatology. The profiles are assimilated by first mapping the depths of the profile to model layers as defined by vertical grid parameters (as described in section 3.1.1). The differences with model state are then treated as perturbations with limitations imposed such that the depth of any layer cannot be made negative and the total water depth at that location is fixed. A more detailed description can be found in (Lozano and Liu 2010). 


\section{EVALUATION OF RESULTS}

Preliminary evaluation of results was focused on two regions which are of significant importance to our customers. These two regions are the Gulf Stream region and Gulf of Maine. While the former represents a region where deep water dynamics determines water mass transformations, the latter has many characteristics of coastal interactions which impact inner shelf currents and mixing. Two other commonly considered metrics for model performance in the North Atlantic are also discussed under the daily monitoring section.

\subsection{Gulf Stream Region}

The Gulf Stream current changes substantially in structure and strength after separation at Cape Hatteras (Hogg 1992). We compare model results with historical observations at three cross stream locations at 73,68 and $55^{\circ} \mathrm{W}$. An approximate location of these sections is shown in Fig. 7.

Figures $8 \mathrm{a}$ and $\mathrm{b}$ show instantaneous cross-stream transects at $73^{\circ} \mathrm{W}$ for temperature, normal velocity, and tangential velocity for the upper $2000 \mathrm{~m}$ of water depths from RTOFS and from Halkin and Rossby (1985). The shape of the isotherms as well as those of velocity components compare well with the observed profiles published in Halkin and Rossby (1985). The observed sections of temperature and velocity were obtained with the Pegasus instrument for the upper $2000 \mathrm{~m}$ for a transect crossing the Gulf
Stream at $73^{\circ} \mathrm{W}$. These results suggest that near $73^{\circ} \mathrm{W}$, the Gulf Stream has a well defined dynamical structure in the vertical which has little variability in time and space. This can be attributed to the fact that after separation most of the eddy kinetic energy is associated with the meanders of the Gulf Stream. The magnitude of maximum normal velocity of approximately $2 \mathrm{~m} \mathrm{~s}^{-1}$ at $200 \mathrm{~m}$ depth also compares well to measured values but the perpendicular (or tangential) velocities at this section from RTOFS are much weaker. The meandering nature of the Gulf Stream leads to a large spatial (horizontal) variability in the values of tangential velocities.

In Fig. 9, a similar cross-stream transect is compared at $55^{\circ} \mathrm{W}$ to results reported by Bower and Hogg (1996) at the same location. Bower and Hogg (1996) conducted field experiments for two years at $55^{\circ} \mathrm{W}$ where they took direct current measurements using an array of current meter moorings. They measured velocity throughout the water column. Here too, RTOFS is able to capture the more axisymmetric shape of the average normal velocity component and the magnitudes also compare well. The deepening barotropic nature of the Gulf Stream is easily seen in comparing shapes with those reported at $73^{\circ} \mathrm{W}$. This increase in transports associated with Gulf Stream is shown in Fig. 10. Even though, the primary density structure remains the same for most of the eastward propagation of the Gulf Stream, the barotropic velocity component of the Gulf Stream increases fivefold from 73 to $55^{\circ} \mathrm{W}$. Though unlike at $73^{\circ} \mathrm{W}$, the average

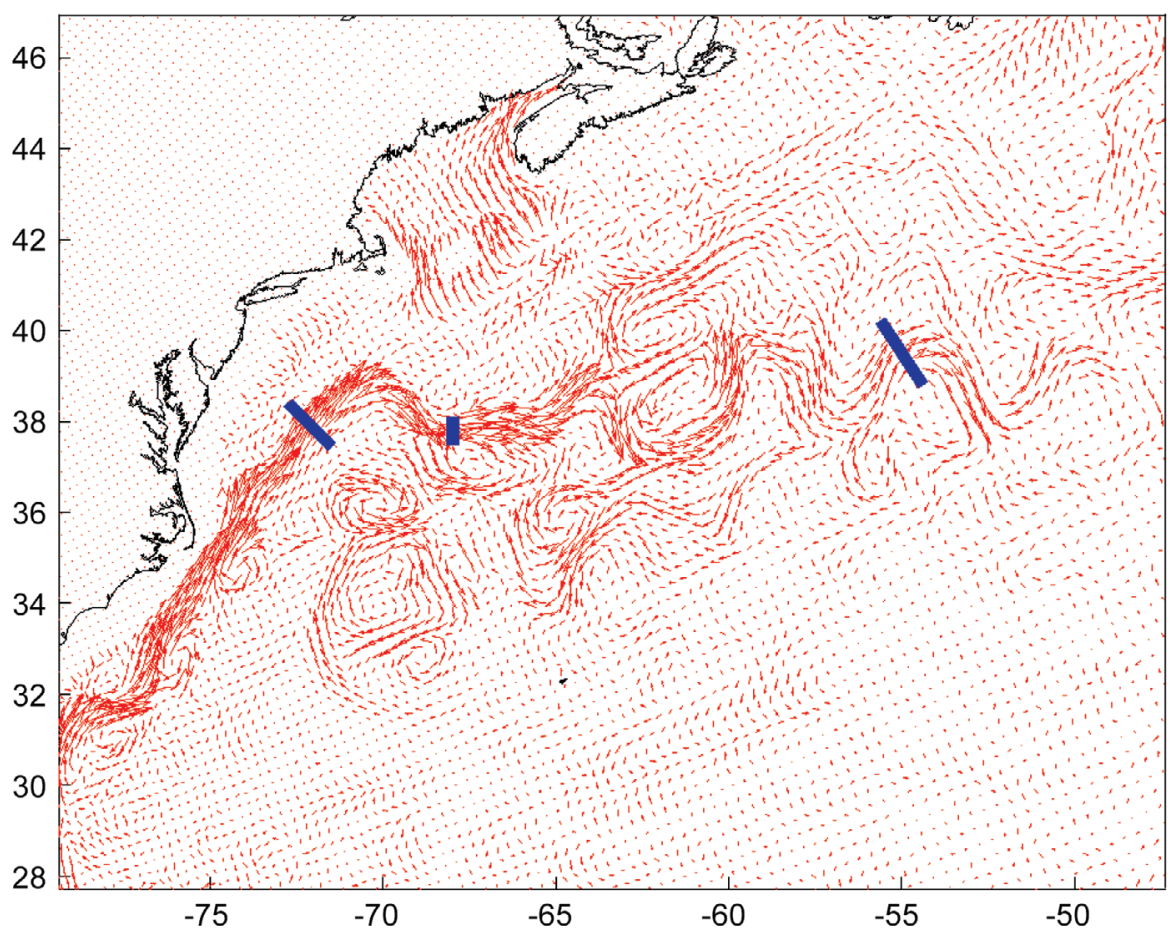

Fig. 7. Across Gulf Stream Sections at $\sim 73,68$ and $55^{\circ} \mathrm{W}$. 
synoptic Gulf Stream at $55^{\circ} \mathrm{W}$ is strongly influenced by the deep anticyclones and cyclones beneath the surface flow with strong coupling between the upper and lower layers (Shay et al. 1995). The mean observations of Gulf Stream transports in Fig. 10 were taken from those reported in literature (Halkin and Rossby 1985; Shay et al. 1995; Bower and Hogg 1996). The error bars on RTOFS results repre- sent the standard deviation of model results computed over a time period of one year.

In summary, the observed eastward increases in the Gulf Stream transport and its barotropization are well matched in the mean by results from RTOFS. The observed slanted velocity and temperature profiles are also captured by model predictions. (a)

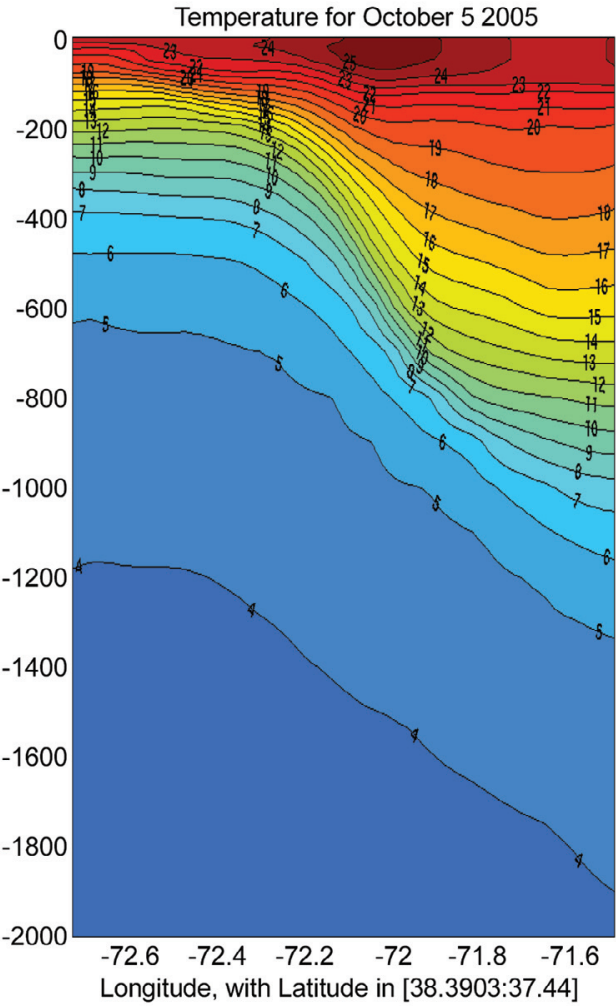

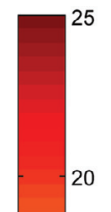

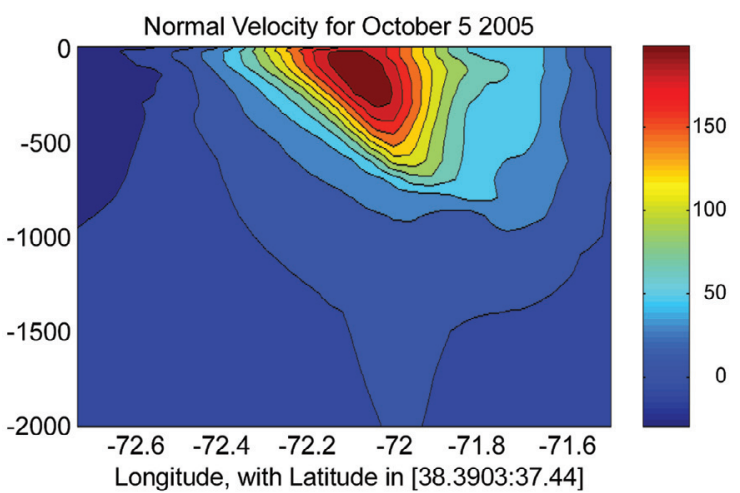

10

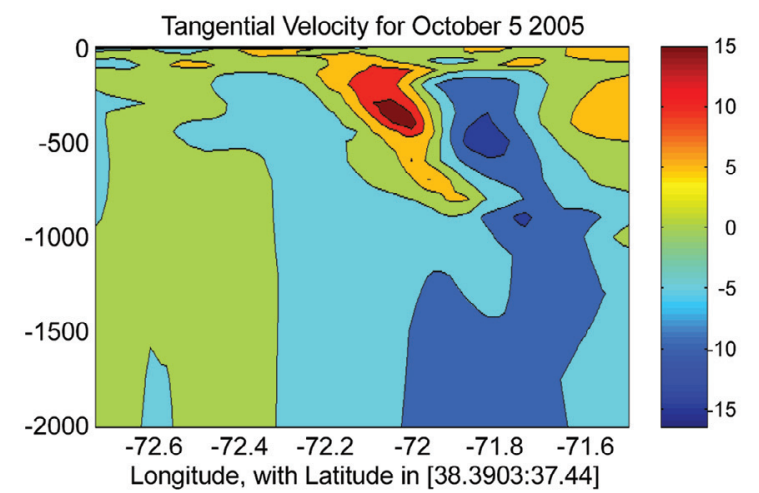

(b)
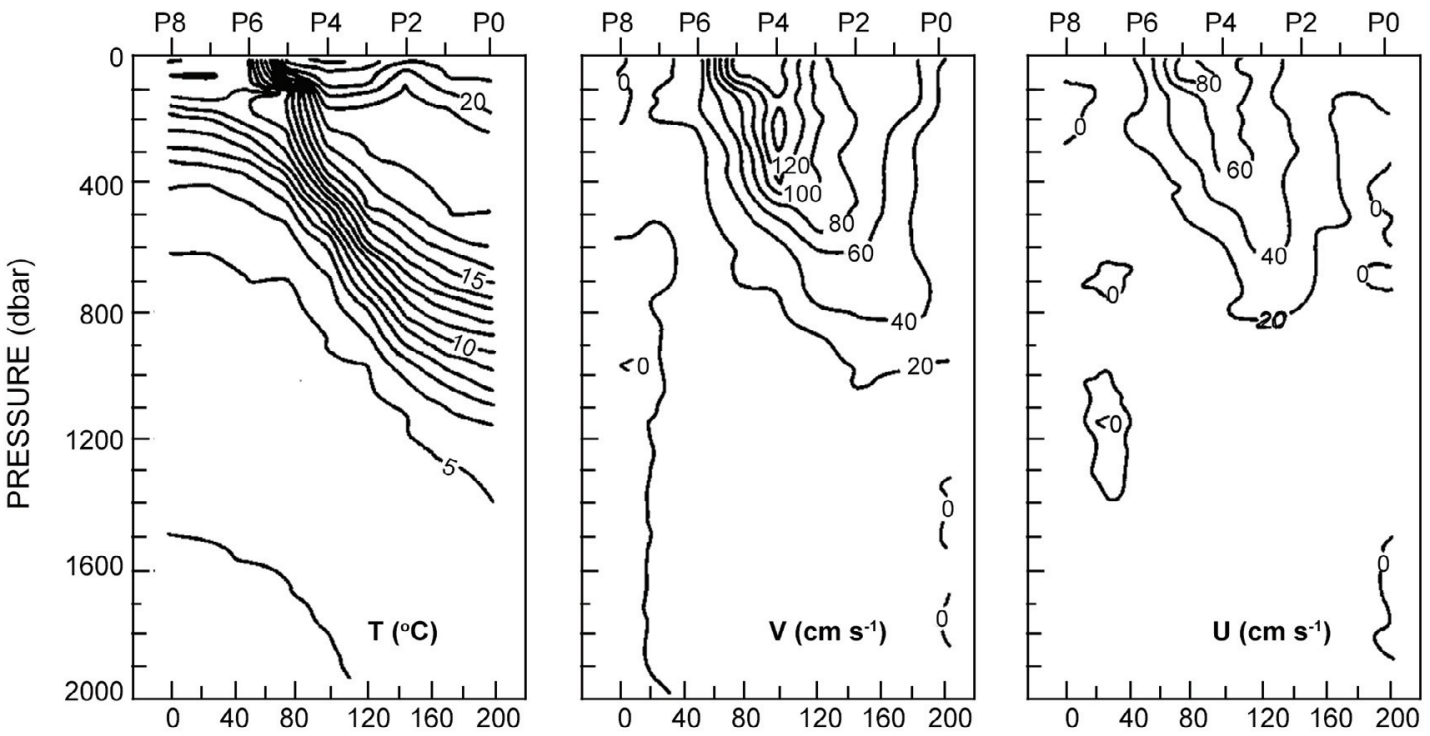

CROSS STREAM DISTANCE $(\mathrm{km})$

Fig. 8. (a) Transect from RTOFS at $73^{\circ} \mathrm{W}$. The right panel shows temperatures (in deg. C) in the upper $2000 \mathrm{~m}$ depth, while the left panel shows normal (top) and tangential (bottom) velocities in $\mathrm{cm} \mathrm{s}^{-1}$. (b) Transect at $73^{\circ} \mathrm{W}$ [Fig. 4 from Halkin and Rossby (1985)]. 

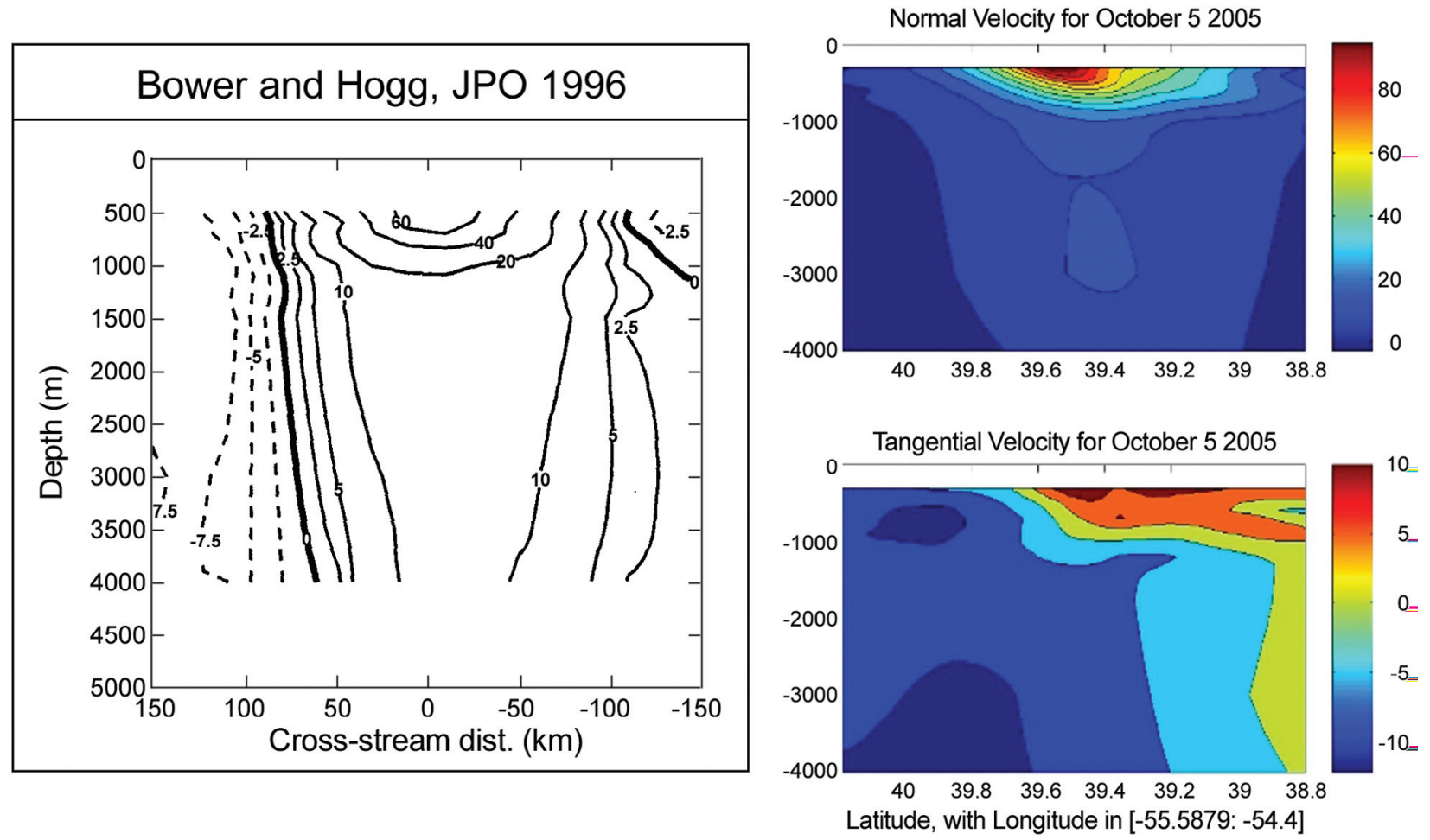

Fig. 9. Transect from RTOFS at $55^{\circ} \mathrm{W}$. The left panel shows normal velocity as presented by Bower and Hogg (1996). The right panels shows normal (top) and tangential (bottom) velocities in $\mathrm{cm} \mathrm{s}^{-1}$ from RTOFS.

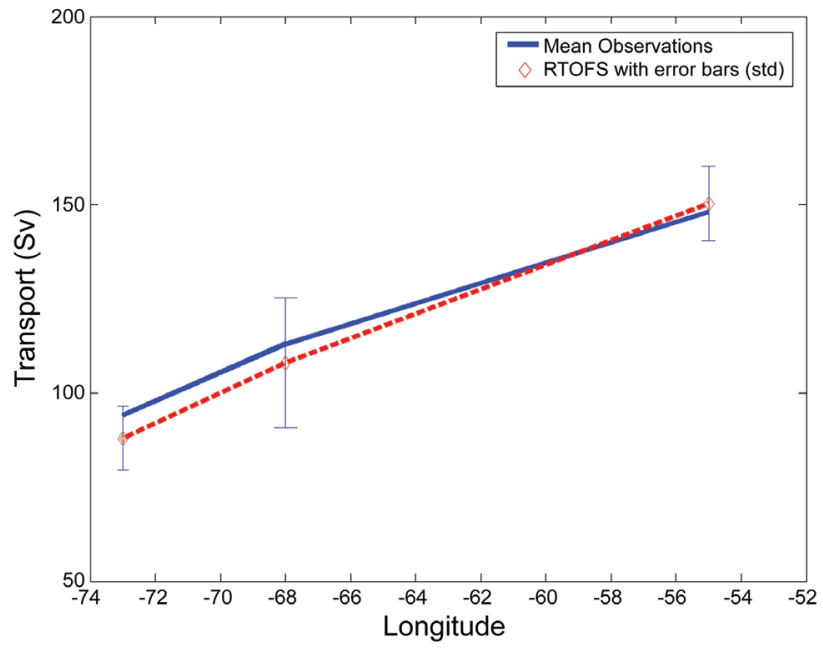

Fig. 10. Mean transports at the selected three sections $(73,68$ and $55^{\circ} \mathrm{W}$ ) from RTOFS compared to those computed from field experiments.

\subsection{Gulf of Maine}

The circulation in the Gulf of Maine has a distinct seasonal pattern where a cyclonic gyre sets up during late spring and early summer and continues to strengthen during late summer and autumn. This set up has been attributed primarily to differential surface heating between the interior of the Gulf and shelf slope region (Xue et al. 2000). This set up weakens during winter as this differential ends and bottom friction acts to dissipates the pattern. Some other factors which influence the overall patterns in the Gulf are wind forcing, river runoff, deep (slope water) inflows and coastal (Scotian Shelf) inflows and tidal mixing.

The late summer surface circulation pattern can be easily seen in Fig. 11. It primarily consists of a cyclonic gyre along the perimeter and enclosed by an anticyclonic circulation on the Georges Bank and two other smaller cyclonic cells in the eastern Gulf of Maine which are not well documented nor mechanisms behind them well understood. This can be compared to a monthly mean surface pattern from RTOFS for the month of September in Fig. 12. A weak cyclonic circulation pattern is interrupted by a strong coastal current near Cape Cod. The model is able to produce a strong anticyclonic pattern over Georges Bank but the two cyclonic gyres are mostly absent in the eastern Gulf.

For the month of July, mean freshwater transports associated with the perimeter cyclonic current in the Northwest Gulf of Maine were computed. The results are shown in Fig. 13 for sections marked on the figure (in blue). On comparing these results with those obtained from current meter measurements by Geyer et al. (2004), RTOFS underpredicts the strength of these by around $190 \mathrm{~m}^{3} \mathrm{~s}^{-1}$ or approximately $15 \%$. For this comparison, the freshwater transports are defined as those associated with a salinity of $32.0 \mathrm{ppt}$ or less. 


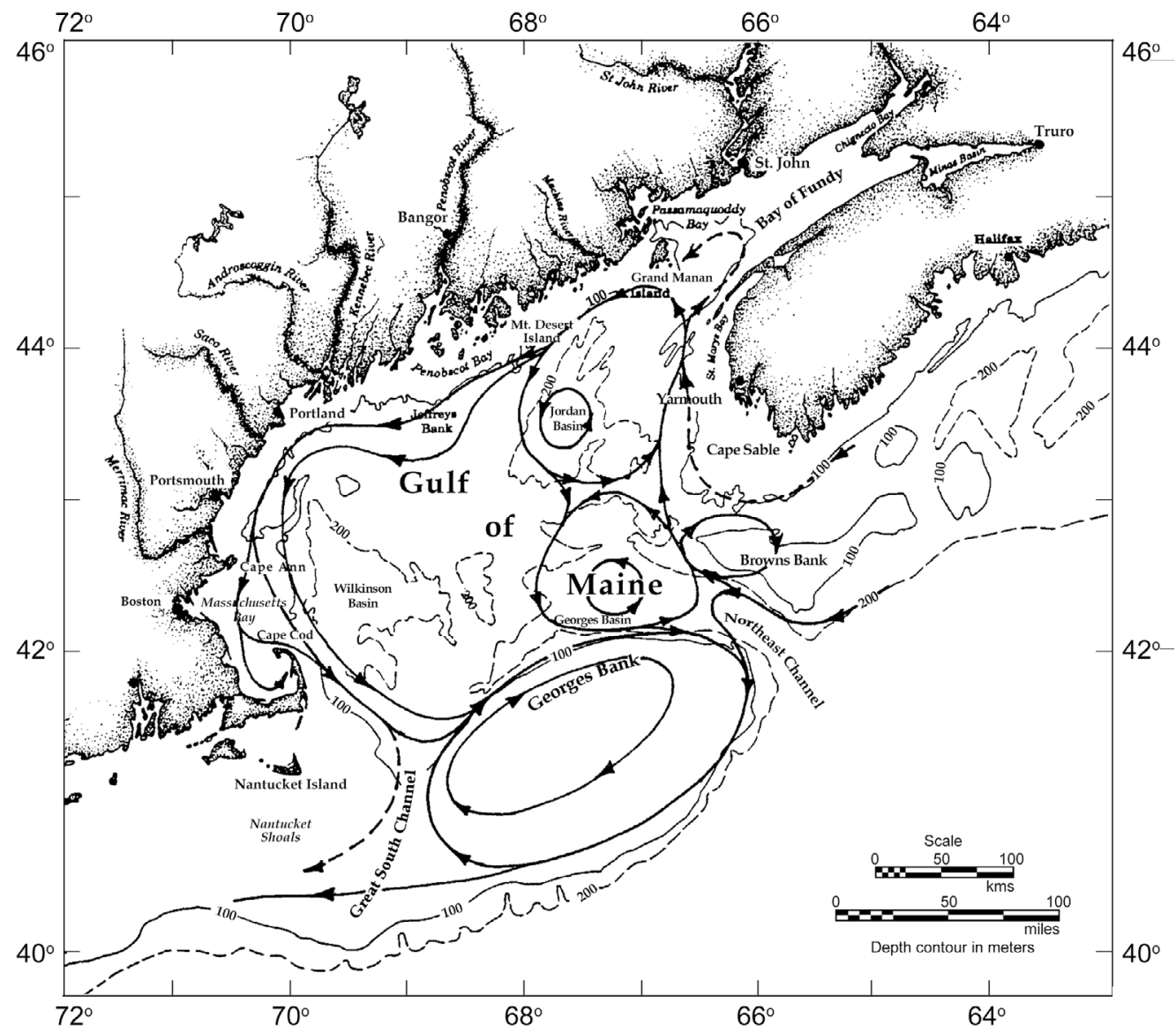

Fig. 11. The Gulf of Maine mean surface circulation from Xue et al. (2000).

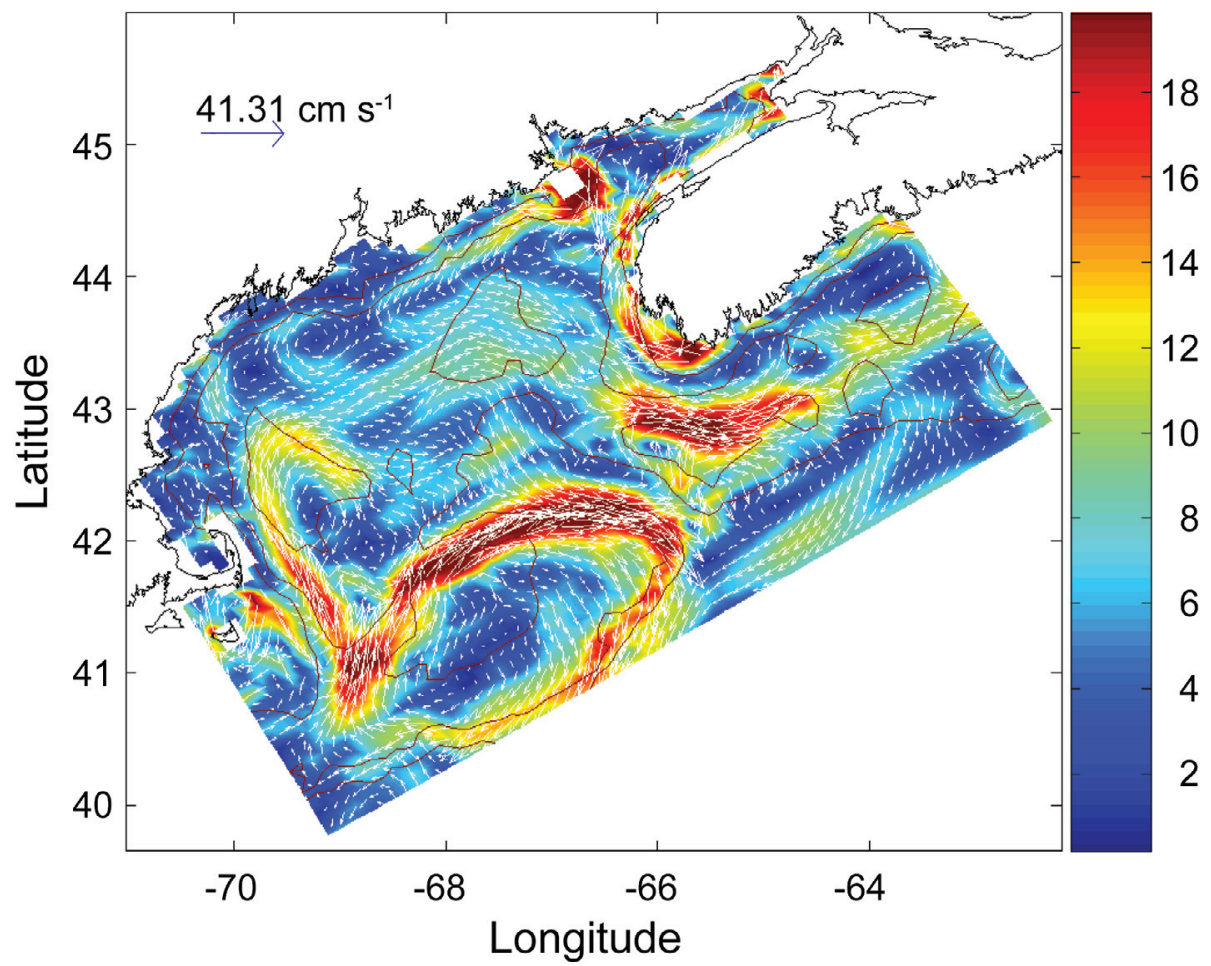

Fig. 12. Mean monthly surface circulation in Gulf of Maine from RTOFS for the month of September. 


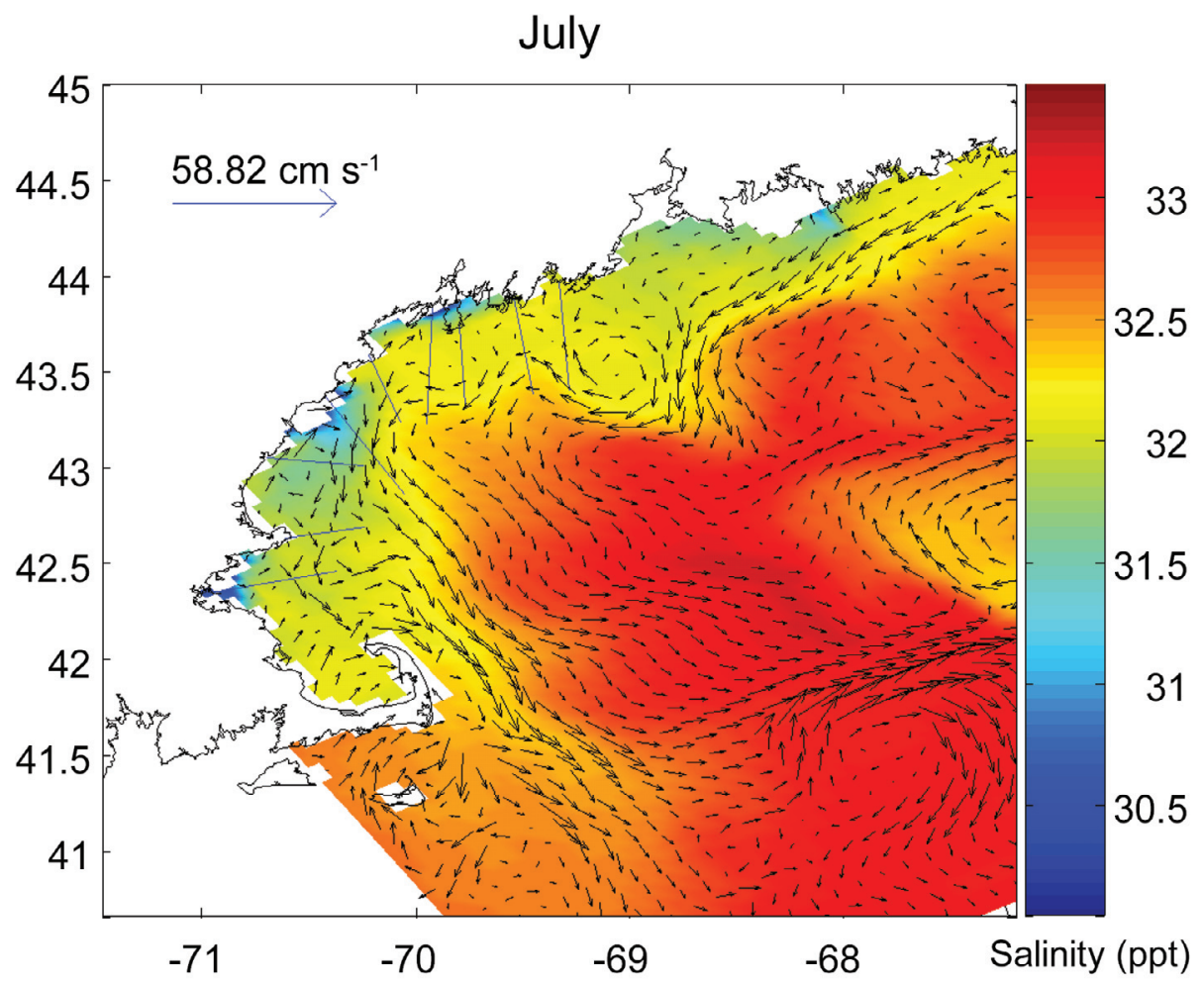

Fig. 13. The sections (in blue) are shown where the freshwater transport is calculated. RTOFS gave a monthly mean of $1149.1 \mathrm{~m}^{3} \mathrm{~s}^{-1}$ which can be compared to transports reported by Geyer et al. (2004) of $1338.9 \mathrm{~m}^{3} \mathrm{~s}^{-1}$.

Water levels in Gulf of Maine were also compared to tide gauges in Bay of Fundy and in the western half of the Gulf. The results compared well in amplitudes but the phases were off which is evident from maps of co-amplitudes and co-phases in Fig. 14 from RTOFS (right panel) and from NOAA Atlas of Tidal Elevations (left panel) for the $\mathrm{M}_{2}$ tidal component. On average, phases were off by almost $40^{\circ}$ or approximately 1.4 hours. This phase shift is due to the artificial location of the model boundary dissecting the Davis Straits (Fig. 6) which is a region of strong tidal currents. Efforts are ongoing to recalibrate the tidal boundary conditions applied to this boundary by using more recent data from Egbest and Erofeeva (2002).

\subsection{Daily Monitoring}

One of the most commonly used metrics for Gulf Stream prediction is the location of the North Wall of the Gulf Stream. As an approximation, this position has been defined in the literature (Rossby 1999) as the location of the $12^{\circ}$ isotherm at $400 \mathrm{~m}$ depth. Fig. 15 shows the location of the Gulf Stream North Wall from RTOFS in May 2007 as compared to the one provided by US Navy personnel (personal communication) based on feature analysis of remotely sensed SST data. The observed estimate is discontinuous primarily due to a lack of SST data for the Navy's analysis in regions suffering from cloud cover which is a regular occurence.

The calculated North Wall position from RTOFS tends to overshoot at the separation point near Cape Hatteras (not shown) but compares well to SST based estimates east of $70^{\circ} \mathrm{W}$. Beyond $65^{\circ} \mathrm{W}$, the model is unable to faithfully reproduce the location of meanders and shed eddies but the average position of the North Wall is maintained.

A metric for the daily strength of the sub-tropical circulation gyre is a comparison with the daily measurement of transport between Florida's east coast and the Bahamas using a submarine cable. As described in Larsen (1992), when ions in seawater are advected by ocean currents through the magnetic field of the Earth, an electric field is produced perpendicular to the direction of the water motion whose voltage can be measured using a cabel laid across the path of the ocean currents. This voltage can be in turn correlated to the strength of the ocean current. The location of this cable to measure Florida Current is shown in Fig. 16 along with the nearest model grid points. Figure 16 also shows daily values from the cable data along with its RMS error compared to the transports calculated from daily RTOFS nowcasts for a number of days last year. The detided data from RTOFS (production curve in Fig. 16) tends mostly to overpredict the data from cable indicating a stronger (on some days as much as by $10 \mathrm{~Sv}$ ) sub-tropical gyre. Larger transports in the Florida Current which become part of the Gulf Stream 
also contribute to overshoots of the Gulf Stream near separation at Cape Hatteras, as noted earlier.

\section{CONCLUSIONS}

The RTOFS-Atlantic system described in this paper is the first realtime ocean forecast system based on the HY-
COM ocean model at NCEP. It runs daily and provides a one-day nowcast and a six-day forecast of the Atlantic basin which extends from $25^{\circ} \mathrm{S}$ to $72^{\circ} \mathrm{N}$ and from $98^{\circ} \mathrm{W}$ to $16^{\circ} \mathrm{E}$. This system has been operational since December 2005. Some preliminary evaluations of model performance have been presented which indicate that the model predictions compare well to historical observations but are only

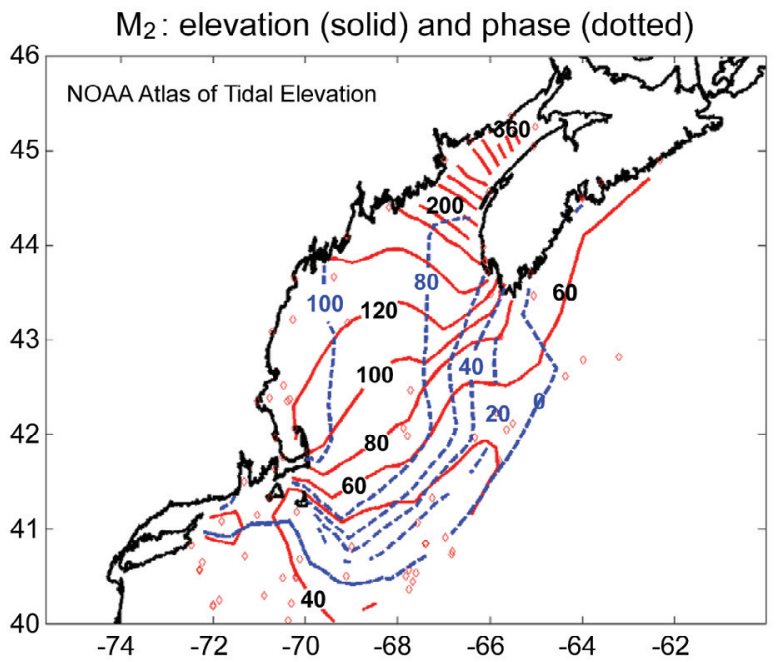

$\mathrm{M}_{2}$ : elevation (red solid) and phase (blue dashed)

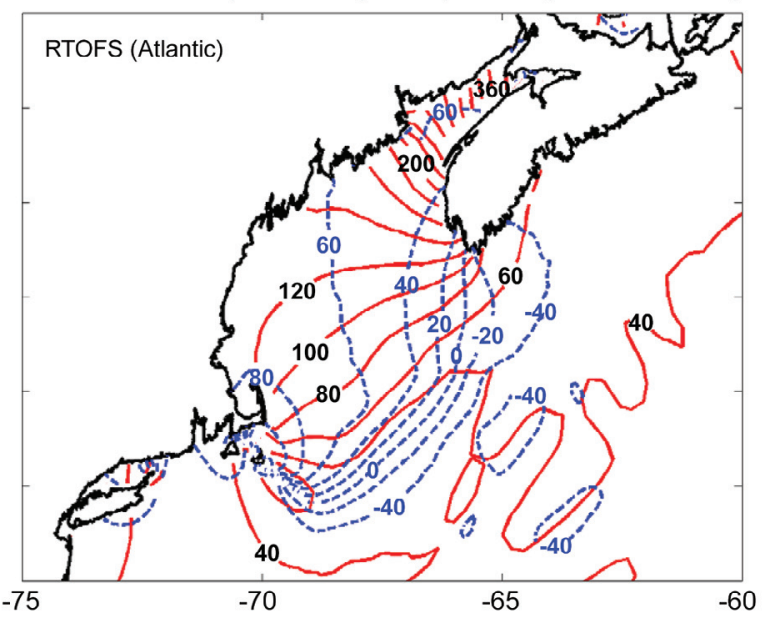

Fig. 14. $\mathrm{M}_{2}$ tidal component in the Gulf of Maine. Co-amplitudes are in red while Co-phases are in blue.

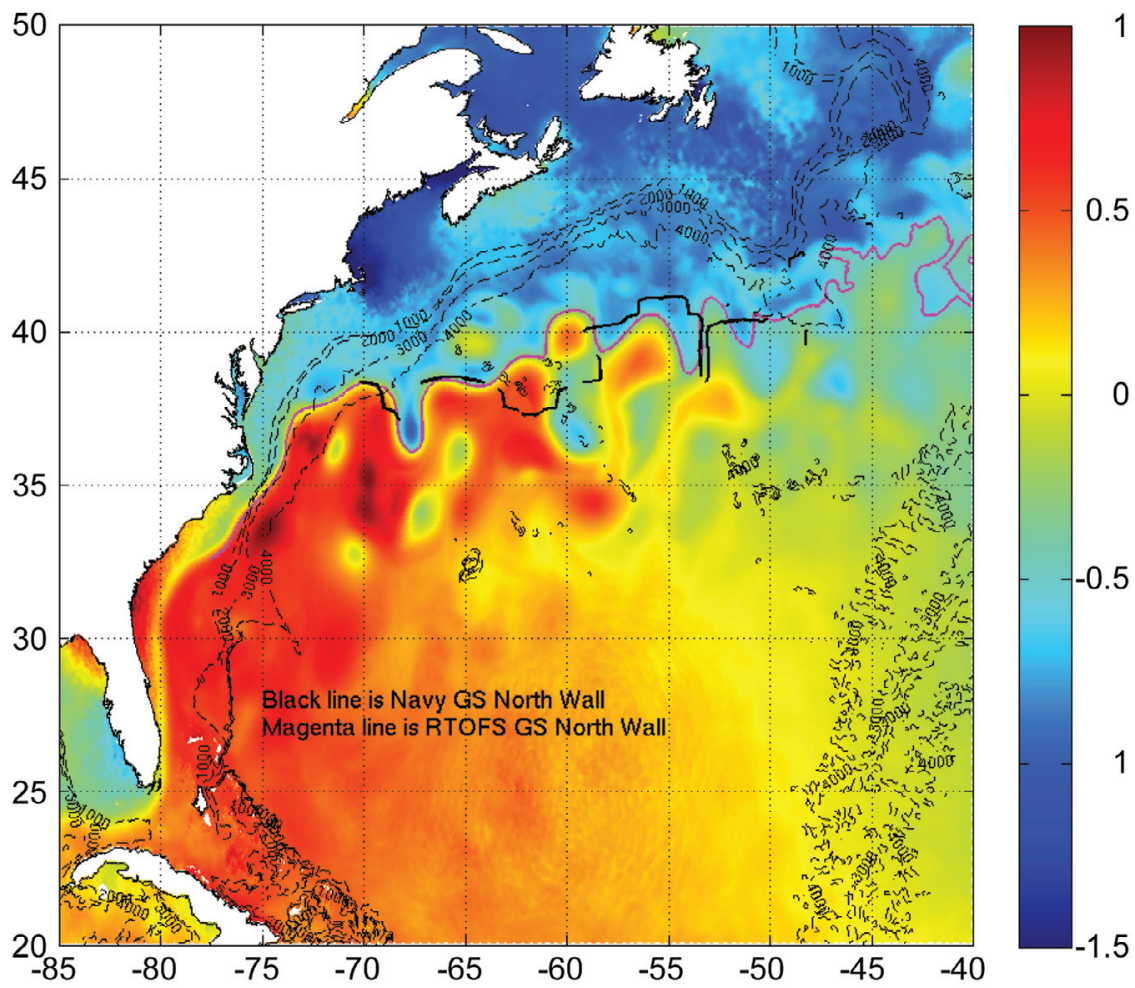

NCEP/EMC/MMAB RTOFS (Atlantic) Navy Frontal Analysis for 08-May-2007

10 May 2007

Fig. 15. North Wall of the Gulf Stream from RTOFS (in magenta), Navy Analysis (in black) superposed on model SSH. 
(a) West Palm Beach, Florida to Eight Mile Rock, Grand Bahamas

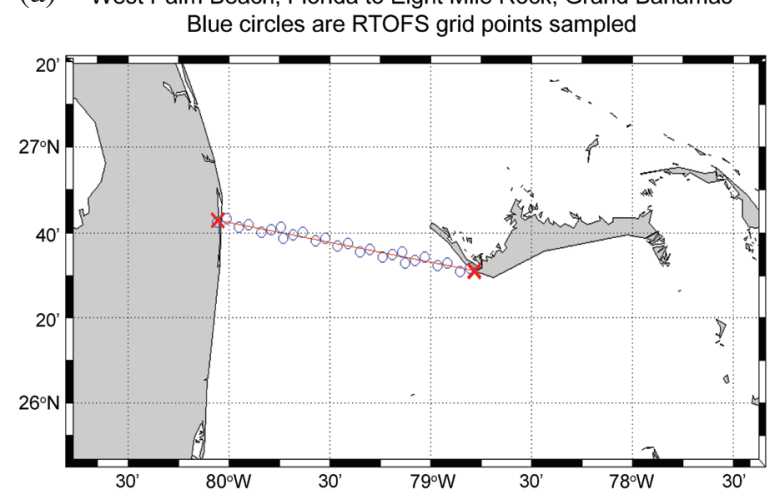

(b)

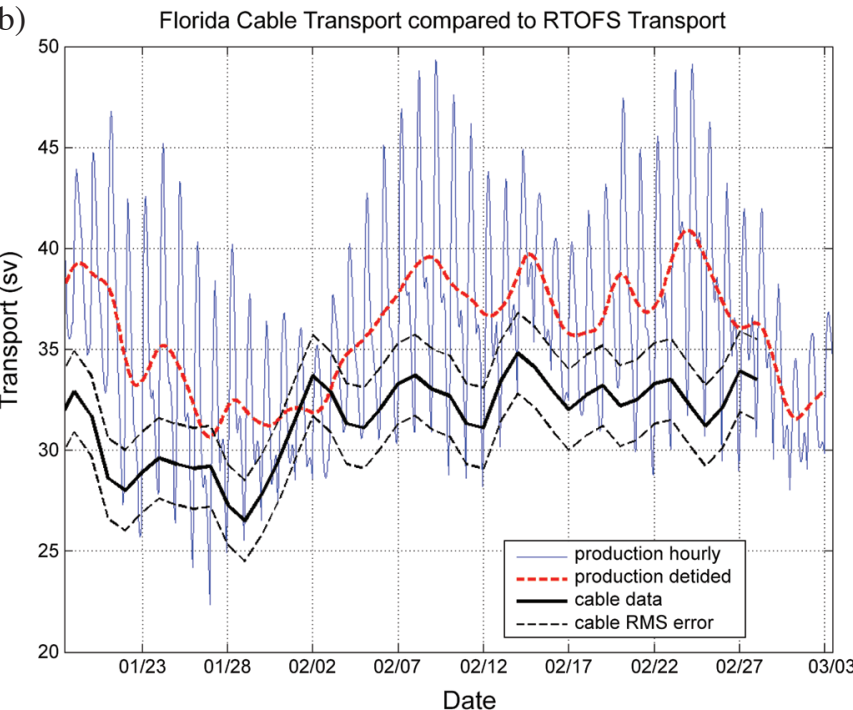

Fig. 16. The location of the cable (a) along with the sampled model grid points. Daily transports from the model compared to those reported from the cable (b).

partly able to capture the daily variability of mesoscale features, fronts and associated transports. Efforts are continueing to improve the system to perform better in forecasting location of both coastal and deep water fronts especially those associated with the US eastern seaboard, Gulf of Mexico and the Gulf Stream.

A similar system based on HYCOM has been under development by the US Navy for the global ocean at 2/25ths of a degree resolution. For the near future, this global ocean forecast system will be implemented operationally at both the US Naval Oceanographic Office and NCEP. Such a system can be used to provide regional boundary conditions for other basin-wide ocean forecast systems including RTOFSAtlantic.

Acknowledgements The authors would like to acknowledge all the members of the RTOFS team who worked diligently in making this system operational. A significant amount of original development and testing was accomplished under the leadership of Dr. Carlos Lozano and Dr. D. B. Rao. Others who spent many hours in building this system include Dr. Chandrasekher Narayanan (targeting, climatology, rivers), Dr. Iris Lohmann (tides, boundary conditions), Ms. Vera Gerald (data assimilation, rivers), Dr. Robert Grumbine (bathymetry, evaluation), Mr. Dan Iredell (scripting), Ms. Bhavani Balasubramaniyam (scripting, post-processing), Dr. Deanna Spindler (data assimilation, analysis) and Dr. Todd Spindler (graphics, analysis).

\section{REFERENCES}

Bleck, R., 2002: An oceanic general circulation model framed in hybrid isopycnic-cartesian coordinates.
Ocean Model. , 4, 55-88, doi: 10.1016/S1463-5003(01) 00012-9. [Link]

Blumberg, A. F. and G. L. Mellor, 1987: A description of a three dimensional coastal ocean Circulation Model. In: Heaps, N. S., (Ed.), Three Dimensional Coastal Ocean Models, 4, American Geophsysical Union, Washington, DC, 1-16.

Bower, A. S. and N. G. Hogg, 1996: Structure of the Gulf Stream and its recirculations at $55^{\circ} \mathrm{W}$. J. Phys. Oceanogr., 26, 1002-1022, doi: 10.1175/1520-0485(1996)02 6<1002:SOTGSA $>2.0 . C O ; 2$. [Link]

Breaker, L. C., D. B. Rao, J. G. W. Kelly, I. Rivin, and B. Balasubramaniyam, 2004: Development of a real-time regional ocean forecast system with application to a domain off the U.S. East Coast. Mar. Technol. Soc. J., 38, 61-79, doi: 10.4031/002533204787522424. [Link]

Browning, G. L. and H. O. Kriess, 1982:. Initialization of the shallow water equations with open boundaries by the bounded derivative method. Tellus, 34, 334-351.

Canuto, V. M., A. Howard, Y. Cheng, and M. S. Dubovikov, 2001: Ocean turbulence. Part I: One-point closure model-momentum and heat vertical diffusivities. $J$. Phys. Oceanogr., 31, 1413-1426, doi: 10.1175/1520-0 485(2001)031<1413:OTPIOP>2.0.CO;2. [Link]

Chao, Y., Z. Li, J. C. Kindle, J. D. Paduan, and F. P. Chavez, 2003: A high-resolution surface vector wind product for coastal oceans: Blending satellite scatterometer measurements with regional mesoscale atmospheric model simulations. Geophys. Res. Lett., 30, 1013, doi: 10.1029/2002GL015729. [Link]

Chassignet, E. P., H. E. Hurlbert, O. M. Smedstad, G. R. Halliwell, A. J. Wallcraft, E. J. Metzger, B. O. Blanton, C. J. Lozano, D. B. Rao, P. J. Hogan, and A. 
Srinivasan, 2006: Generalized vertical coordinates for eddy-resolving global and coastal ocean forecasts. Oceanography, 19, 118-129.

Chelton, D. B., R. A. Deszoeke, and M. G. Schlax, 1998: Geographical variability of the first-baroclinic Rossby radius of deformation. J. Phys. Oceanogr., 28, 433-460, doi: 10.1175/1520-0485(1998)028<0433:GVOTFB $>2$. 0.CO;2. [Link]

Cooper, M. and K. Haines, 1996: Altimetric assimilation with water property conservation. J. Geophys. Res., 101, 1059-1077.

Cuny, J., P. B. Rhinesa, and R. Kwokb, 2005: Davis Strait volume, freshwater and heat fluxes. Deep-Sea Res. I, 52, 519-542, doi: 10.1016/j.dsr.2004.10.006. [Link]

Dunlap, E. and C. C. L. Tang, 2006: Modeling the mean circulation of Baffin Bay. Atmos.-Ocean, 44, 99-110.

Egbert, G. D. and S. Y. Erofeeva, 2002: Efficient inverse modeling of barotropic ocean tides. J. Atmos. Ocean. Technol., 19, 183-204, doi: 10.1175/1520-0426(2002)0 19<0183:EIMOBO>2.0.CO;2. [Link]

Flather, R. A., 1976: A tidal model of the northwest European continental shelf. Mem. Soc. R. Sci. Liege, 10, 141-164.

Foreman, M. G. G., R. F. Henry, R. A. Walters, and V. A. Ballantyne, 1993: A finite element model for tides and resonance along the north coast of British Columbia. $J$. Geophys. Res., 98, 2509-2531.

Geyer, W. R., R. P. Signell, D. A. Fong, J. Wang, D. M. Anderson, and B. A. Keafer, 2004: The freshwater transport and dynamics of the western Maine coastal current. Cont. Shelf Res., 24, 1339-1357, doi: 10.1016/j. csr.2004.04.001. [Link]

Halkin, D. and T. Rossby, 1985: The structure and transport of the Gulf Stream at $73^{\circ}$ W. J. Phys. Oceanogr., 15, 1439-1452, doi: 10.1175/1520-0485(1985)015<1439: TSATOT>2.0.CO;2. [Link]

Halliwell, G, 2001. HYCOM Surface Fluxes. Technical Note. [Link]

Halliwell, G. R., 2004: Evaluation of vertical coordinate and vertical mixing algorithms in the HYbrid-Coordinate Ocean Model (HYCOM). Ocean Model., 7, 285-322, doi: 10.1016/j.ocemod.2003.10.002. [Link]

Hogg, N. G., 1992: On the transport of the Gulf Stream between Cape Hatteras and the Grand Banks. DeepSea Res. A, 39, 1231-1246, doi: 10.1016/0198-0149 (92)90066-3. [Link]

Jerlov, N. G., 1976: Marine Optics. Elsevier Science \& Technology, New York, 231 pp.

Kantha, L. H. and C. A. Clayson, 1999: Numerical Models of Oceans and Oceanic Processes. Academic Press, 940 pages.

Kara, A. B., P. A. Rochford, and H. E. Hurlburt, 2000: Efficient and accurate bulk parameterizations of air-sea fluxes for use in general circulation models. J. Atmos.
Ocean. Technol., 17, 1421-1438, doi: 10.1175/1520-0 426(2000)017<1421:EAABPO>2.0.CO;2. [Link]

Kara, A. B., P. A. Rochford, and H. E. Hurlburt, 2002: Airsea flux estimates and the 1997-1998 ENSO event. Bound.-Layer Meteor., 103, 439-458, doi: 10.1023/A:1 014945408605. [Link]

Larsen, J. C., 1992: Transport and heat flux of the Florida Current at $27^{\circ} \mathrm{N}$ derived from cross-stream voltages and profiling data: Theory and observations. Phil. Trans. R. Soc. Lond. A, 338, 169-236, doi: 10.1098/rsta. 1992.0007. [Link]

Lozano, C. and L. Liu, 2010: Data assimilation in a real time ocean forecast system for the Atlantic. Manuscript under preparation.

Lozier, M. S., W. B. Owens, and R. G. Curry, 1995: The climatology of the North Atlantic. Prog. Oceanogr., 36, 1-44, doi: 10.1016/0079-6611(95)00013-5. [Link]

Mitchell, K. E., D. Lohmann, P. R. Houser, E. F. Wood, J. C. Schaake, A. Robock, B. A. Cosgrove, J. Sheffield, Q. Duan, L. Luo, R. W. Higgins, R. T. Pinker, J. D. Tarpley, D. P. Lettenmaier, C. H. Marshall, J. K. Entin, M. Pan, W. Shi, V. Koren, J. Meng, B. H. Ramsay, and A. A. Bailey, 2004: The multi-institution North American Land Data Assimilation System (NLDAS): Utilizing multiple GCIP products and partners in a continental distributed hydrological modeling system. J. Geophys. Res., 109, D07S90, doi: 10.1029/2003JD003823. [Link]

Moorthi, S., H. L. Pan, and P. Caplan, 2001: Changes to the 2001 NCEP operational MRF/AVN global analysis/ forecast system. NWS Technical Procedures Bulletin, 484, 14.

Mork, M., 1981: Circulation phenomena and frontal dynamics of the Norwegian Coastal Current. Phil. Trans. R. Soc. Lond. A, 302, 635-647, doi: 10.1098/rsta.1981. 0188. [Link]

Niiler, P. P., N. A. Maximenko, and J. C. McWilliams, 2003: Dynamically balanced absolute sea level of the global ocean derived from near-surface velocity observations. Geophys. Res. Lett., 30, 2164 , doi: 10.1029/20 03GL018628. [Link]

Oliger, J. and A. Sundstrom, 1978: Theoretical and practical aspects of some initial boundary value problems in fluid dynamics. SIAM J. Appl. Math., 35, 419-446, doi: 10.1137/0135035. [Link]

Orlanski, I., 1976: A simple boundary condition for unbounded hyperbolic flows. J. Comput. Phys., 21, 251269, doi: 10.1016/0021-9991(76)90023-1. [Link]

Palma, E. and R. Matano, 2000: On the implementation of open boundary conditions for a general circulation model: The three-dimensional case. J. Geophys. Res., 105, 8605-8627.

Penduff, T., B. Barnier, and A. de Verdire, 2000: Selfadapting open boundaries for a sigma coordinate model of the eastern North Atlantic. J. Geophys. Res., 105, 
11279-11297.

Reid, J. L., 1994: On the total geostrophic circulation of the North Atlantic Ocean: Flow patterns, tracers and transports. Prog. Oceanogr., 33, 1-92, doi: 10.1016/00796611(94)90014-0. [Link]

Reid, R. O., 1990: Tides and storm surges. In: Herbich, J. B. (Ed.), Handbook of Coastal and Ocean Engineering, Vol. 1, Wave Phenomena and Coastal Structures, 533-589.

Rio, M.-H. and F. Hernandez, 2004: A mean dynamic topography computed over the world ocean from altimetry, in-situ measurements and a geoid model. J. Geophys. Res., 109, C12032, doi: 10.1029/2003JC002226. [Link]

Rossby, T., 1999: On gyre interactions. Deep-Sea Res. II, 46, 139-164, doi: 10.1016/S0967-0645(98)00095-2. [Link]

Satoh, M., 2004: Atmospheric Circulation Dynamics and General Circulation Models. Springer with Praxis Publishing, UK, $644 \mathrm{pp}$.

Shay, T. J., J. H. Bane, D. R. Watts, and K. L. Tracey, 1995: Gulf Stream flow field and events near $55^{\circ} \mathrm{W}$. J. Geophys. Res., 100, 22565-22589.

Stevens, D. P., 1991: The open boundary condition in the United Kingdom fine-resolution antarctic model. $J$. Phys. Oceanogr., 21, 1494-1499, doi: 10.1175/1520-0 485(1991)021<1494:TOBCIT>2.0.CO;2. [Link]

Stramma, L. and M. England, 1999: On the water masses and mean circulation of the South Atlantic Ocean. J. Geophys. Res., 104, 20863-20883, doi: 10.1029/1999JC90 0139. [Link]

Stramma, L. and F. Schott, 1999: The mean flow field of the tropical Atlantic Ocean. Deep-Sea Res. II, 46, 279-303, doi: 10.1016/S0967-0645(98)00109-X. [Link]

Tang, C. C. L, C. K. Ross, T. Yao, B. Petrie, B. M. DeTracey and E. Dunlap, 2004: The circulation, water masses and sea-ice of Baffin Bay. Prog. Oceanogr., 63, 183228, doi: 10.1016/j.pocean.2004.09.005. [Link]

Treguier, A., B. Barnier, A. de Miranda, J. Molines, N. Grima, M. Imbard, G. Madec, C. Messager, T. Reynaud, and S. Michel, 2001: An eddy-permitting model of the Atlantic circulation: Evaluating open boundary conditions. J. Geophys. Res., 106, 22115-22129.

Vazquez, J., A. V. Tran, R. Sumagaysay, and E. Smith, 1996: NOAA/NASA AVHRR Oceans Pathfinder Sea Surface Temperature User Reference Manual, Jet Propulsion Laboratory, Pasadena, CA.

Vorosmarty, C. J., B. M. Fekete, and B. A. Tucker. 1996d: Global River Discharge Database (RivDIS v1.0), Vol. 0-6: Europe. International Hydrological Programme, United Nations Educational, Scientific and Cultural Organization, Paris, France.

Wessel, P. and W. H. F. Smith, 1996: A global self-consistent, hierarchical, high-resolution shoreline database. J. Geophys. Res., 101, 8741-8743, doi: 10.1029/ 96JB00104. [Link]

Woodgate, R., E. Fahrbach, and G. Rohardt, 1999: Structure and transports of the East Greenland Current at $75^{\circ} \mathrm{N}$ from moored current meters. J. Geophys. Res., 104, 18059-18072.

Xue, H., F. Chai, and N. R. Pettigrew, 2000: A model study of the seasonal circulation in the Gulf of Maine. $J$. Phys. Oceanogr., 30, 1111-1135, doi: 10.1175/1520-0 485(2000)030<1111:AMSOTS>2.0.CO;2. [Link] 